\title{
Resistance exercise-induced S6K1 kinase activity is not inhibited in human skeletal muscle despite prior activation of AMPK by high-intensity interval cycling
}

\author{
William Apró, ${ }^{1,2}$ Marcus Moberg, ${ }^{1}$ D. Lee Hamilton, ${ }^{3}$ Björn Ekblom, ${ }^{1}$ Gerrit van Hall, ${ }^{4}$ \\ Hans-Christer Holmberg, ${ }^{5}$ and Eva Blomstrand ${ }^{1,6}$ \\ ${ }^{1}$ Åstrand Laboratory, Swedish School of Sport and Health Sciences, Stockholm, Sweden; ${ }^{2}$ Department of Clinical Science, \\ Intervention and Technology, Karolinska Institutet, Stockholm, Sweden; ${ }^{3}$ Health and Exercise Sciences Research Group, \\ University of Stirling, Stirling, United Kingdom; ${ }^{4}$ Department of Biomedical Sciences, Rigshospitalet, University of \\ Copenhagen, Denmark; ${ }^{5}$ Swedish Winter Sports Research Centre, Department of Health Sciences, Mid Sweden University, \\ Östersund, Sweden; and ${ }^{6}$ Department of Physiology and Pharmacology, Karolinska Institutet, Stockholm, Sweden
}

Submitted 20 October 2014; accepted in final form 12 January 2015

\begin{abstract}
Apró W, Moberg M, Hamilton DL, Ekblom B, van Hall G, Holmberg HC, Blomstrand E. Resistance exercise-induced S6K1 kinase activity is not inhibited in human skeletal muscle despite prior activation of AMPK by high-intensity interval cycling. Am J Physiol Endocrinol Metab 308: E470-E481, 2015. First published January 20, 2015; doi:10.1152/ajpendo.00486.2014.-Combining endurance and strength training in the same session has been reported to reduce the anabolic response to the latter form of exercise. The underlying mechanism, based primarily on results from rodent muscle, is proposed to involve AMPK-dependent inhibition of mTORC1 signaling. This hypothesis was tested in eight trained male subjects who in randomized order performed either resistance exercise only $(\mathrm{R})$ or interval cycling followed by resistance exercise (ER). Biopsies taken from the vastus lateralis before and after endurance exercise and repeatedly after resistance exercise were assessed for glycogen content, kinase activity, protein phosphorylation, and gene expression. Mixed muscle fractional synthetic rate was measured at rest and during $3 \mathrm{~h}$ of recovery using the stable isotope technique. In ER, AMPK activity was elevated immediately after both endurance and resistance exercise $(\sim 90 \%, P<0.05)$ but was unchanged in $\mathrm{R}$. Thr ${ }^{389}$ phosphorylation of S6K1 was increased severalfold immediately after exercise $(P<0.05)$ in both trials and increased further throughout recovery. After 90 and 180 min recovery, S6K1 activity was elevated $(\sim 55$ and $\sim 110 \%$, respectively, $P<0.05)$ and eukaryotic elongation factor 2 phosphorylation was reduced $(\sim 55 \%, P<0.05)$ with no difference between trials. In contrast, markers for protein catabolism were differently influenced by the two modes of exercise; ER induced a significant increase in gene and protein expression of MuRF1 $(P<$ 0.05 ), which was not observed following $\mathrm{R}$ exercise only. In conclusion, cycling-induced elevation in AMPK activity does not inhibit mTOR complex 1 signaling after subsequent resistance exercise but may instead interfere with the hypertrophic response by influencing key components in protein breakdown.
\end{abstract}

AMPK; concurrent exercise; S6K1; mTORC1

DIVERSE TRAINING ADAPTATIONS, such as skeletal muscle hypertrophy and increased mitochondrial content, are believed to be mediated by specific signaling pathways (3). For instance, loading-induced muscle accretion has been shown to be largely regulated by the mechanistic target of rapamycin complex 1 (mTORC1) pathway $(7,23)$, while increased mitochondrial

Address for reprint requests and other correspondence: W. Apró, The Swedish School of Sport and Health Sciences, Box 5626, SE-114 86 Stockholm, Sweden (e-mail: william.apro@gih.se). biogenesis and subsequent increase in oxidative capacity has been linked to activation of the peroxisome proliferator-activated receptor coactivator-1 $\alpha$ (PGC-1 $\alpha$ ) pathway (39). Due to the opposing phenotypic adaptations following resistance and endurance exercise, it has been suggested that the adaptive response is diminished when these two modes of exercise are combined (25). From a mechanistic perspective, such molecular interference has been linked to the adenosine monophosphate-activated protein kinase (AMPK), which, when activated by pharmacological agents in rodent muscle, has been shown to inhibit mTORC1 signaling $(8,43)$ but increase mRNA expression of PGC-1 $\alpha$ (30).

Relatively few studies have examined the acute molecular response to different modes of exercise when performed concurrently $(2,14,15,34,35)$. Of these, only one study examined the effect of prior endurance exercise on the resistance exercise-induced activation of the mTORC1 pathway (35). However, in that study, mTORC1 signaling was unchanged in response to resistance exercise in both conditions, thus preventing any conclusions regarding the effect of prior activation of AMPK (35). In contrast, when sprint exercise was undertaken before resistance exercise, the signaling response immediately downstream of mTORC1 was blunted compared with when the exercise sessions were performed in the reverse order (14). However, that study did not include single-mode resistance exercise for comparison (14). Consequently, our understanding of the proposed interference effect of combined endurance and resistance exercise at the molecular level still remains incomplete.

Several mechanisms have been proposed by which AMPK, in response to cellular stress, mediates inhibition of mTORC1 signaling. Upstream regulation includes signaling through the TSC (tuberous sclerosis complex)1/TSC2 complex, which, through alterations in assembly (28) and AMPK-mediated phosphorylation of the $\operatorname{Ser}^{1387}$ residue (29), inhibits mTORC1 activity. AMPK has also been shown to phosphorylate the defining component of $\mathrm{mTORC} 1$, raptor, at the $\mathrm{Ser}^{792}$ residue, which results in suppressed functionality of the complex (24). However, the existence of these inhibitory mechanisms of AMPK signaling on the mTORC1 pathway in human skeletal muscle remains unknown.

Therefore, the aim of this study was to examine whether increased AMPK activity, as a result of prior high-intensity interval cycling, would inhibit resistance exercise-induced 
mTORC1 signaling in relatively well-trained subjects compared with single-mode resistance exercise. To gain mechanistic insight into the AMPK-mediated regulation of mTORC1 signaling, TSC1/2 complex assembly was assessed as well as the phosphorylation status of the AMPK targets TSC2 and raptor. Furthermore, in addition to measuring S6K1 phosphorylation, kinase activity of this enzyme was measured to gain quantitative assessment of the potential interference of AMPK on the mTORC1 pathway. Last, the stable-isotope technique was employed to determine whether alterations in signaling, protein-protein interaction, and kinase activity would be reflected in similar changes in the rate of protein synthesis. Our hypothesis was that high-intensity cycling, when performed prior to resistance exercise, would inhibit the mTORC1 pathway through AMPK-mediated elevations in TSC2 and raptor phosphorylation.

\section{METHODS}

Subjects. Eight healthy, moderately trained male subjects were recruited for this study. After being informed of the purpose of the study and of all associated risks, all subjects gave written consent. The study was approved by the Regional Ethical Review Board in Stockholm and performed in accordance with the principles outlined in the Declaration of Helsinki. To be eligible for enrollment in the study, subjects were required to have performed resistance exercise 2-3 times a week and endurance exercise 1-2 times a week during the previous 6 mo and to have a maximal leg strength equaling four times their body weight or more. Subject characteristics were as follows: the mean $( \pm \mathrm{SE})$ age was $26 \pm 2 \mathrm{yr}$, height $183 \pm 2 \mathrm{~cm}$, weight $85 \pm 2$ $\mathrm{kg}$, maximal leg strength $432 \pm 15 \mathrm{~kg}$, maximum oxygen uptake $4.6 \pm 0.2 \mathrm{l} / \mathrm{min}$, and maximum cycling power output $361 \pm 16 \mathrm{~W}$. The study employed a randomized cross-over design in which each subject performed one session of high-intensity interval cycling followed by resistance exercise (ER) and another session of resistance exercise only $(\mathrm{R})$. The two sessions were separated by $\sim 2$ wk. A schematic overview of the experimental protocols is provided in Fig. 1. All subjects were instructed to maintain their habitual dietary intake and physical activity pattern throughout the entire experimental period. Subjects were instructed to refrain from physical exercise for 2 days before each trial as well as to record and duplicate their food intake before the first and second trials, respectively.

Pretests. Before initiation of the actual experiments, each subject's two-legged one-repetition maximum (1RM) was determined on a leg press machine (243 Leg Press $45^{\circ}$; Gymleco, Stockholm, Sweden) after warming up on a cycle ergometer for $10 \mathrm{~min}$. The 1RM was assessed by gradually increasing the load until the subject was unable to perform more than one single repetition $\left(90-180^{\circ}\right.$ knee angle). Maximal and submaximal oxygen uptake was determined on a mechanically braked cycle ergometer (Monark 839E, Vansbro, Sweden), with the work rate gradually increased until volitional exhaustion as described by Åstrand and Rodahl (2a). Oxygen uptake was measured continuously utilizing an on-line system (Oxycon Pro; Erich Jaeger, Hoechberg, Germany), and heart rate (HR) was recorded continuously (Polar Electro Oy, Kempele, Finland). Following initial testing, subjects performed three familiarization sessions to minimize any training effects during the live experiments. During these three sessions, subjects performed the ER protocol, wherein the intensity of the cycling and the load of the leg-press exercise were adjusted so the subjects could perform the designated protocol. Thus, the load and number of repetitions determined during the last familiarization session were used in both experimental trials.

Experimental trials. On the day of each trial, subjects reported to the laboratory at 5:30 AM following an overnight fast from 9:00 PM the evening before. Upon arrival, subjects were placed in a supine position, and catheters were placed in the antecubital vein of both arms. One arm was used for blood sampling and the other arm for the stable isotope infusion. Following a 30-min resting period, a baseline blood sample was collected, after which a primed constant infusion of $\mathrm{L}-\left[\right.$ ring $\left.{ }^{13} \mathrm{C}_{6}\right]$ phenylalanine $\left(0.05 \mu \mathrm{mol} \cdot \mathrm{kg}^{-1} \cdot \mathrm{min}^{-1}\right.$, prime $2 \mu \mathrm{mol} /$ $\mathrm{kg}$; Cambridge Isotope Laboratories, Danvers, MA) was initiated and maintained for the duration of the entire experiment $(\sim 10 \mathrm{~h})$. Two hours after the initiation of the tracer infusion, the first resting biopsy was collected under local anaesthesia [2-3 ml Xylocaine (Lidocaine); AstraZeneca, Södertälje, Sweden] from the distal portion of the vastus lateralis muscle of one leg, using a Weil-Blakesley conchotome (AB Wisex, Mölndal, Sweden). To obtain resting values of mixed muscle

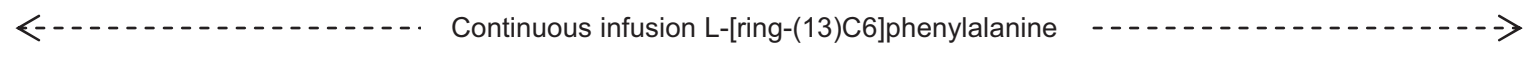

\section{ER - protocol}

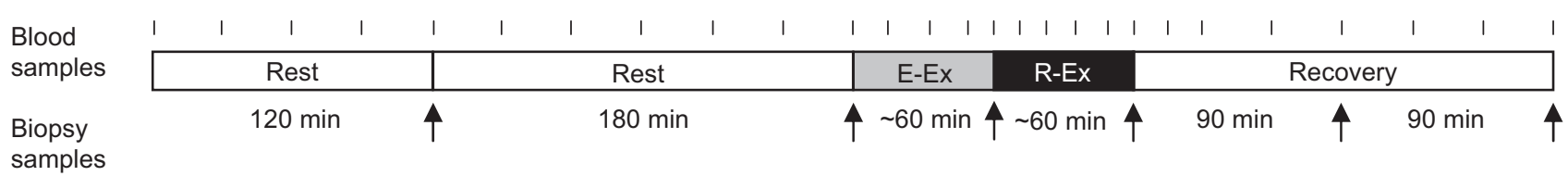

\section{R - protocol}

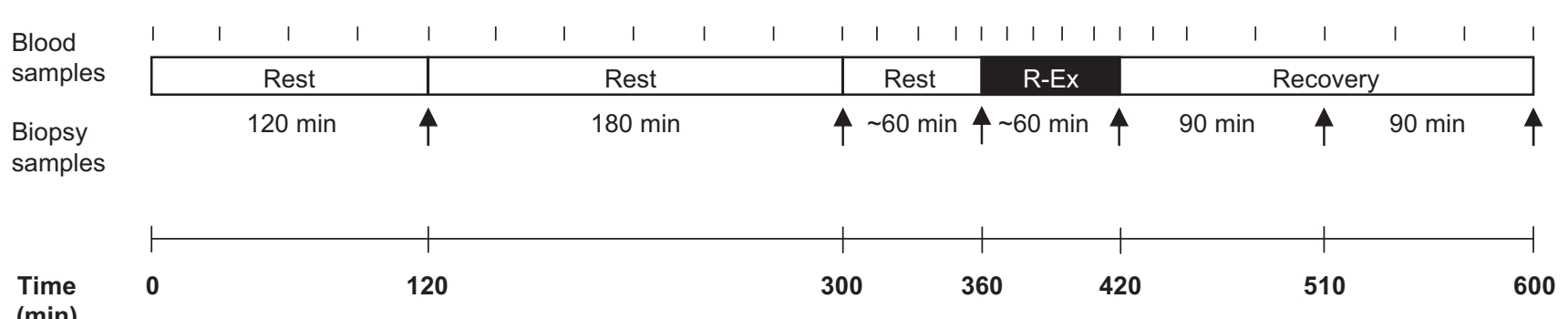

Fig. 1. Schematic overview of the experimental trials. ER protocol, interval cycling followed by resistance exercise; R protocol, resistance exercise only. Arrows indicate sampling time points for muscle biopsies; vertical lines indicate sampling time points for blood. 
protein synthesis, a second resting biopsy was collected $3 \mathrm{~h}$ later. During these initial $5 \mathrm{~h}$ of rest and tracer infusion, blood samples were drawn every 30 min into EDTA tubes.

Following tissue and blood sampling, in the ER trial, subjects warmed up on the cycle ergometer for a total of $15 \mathrm{~min}(5 \mathrm{~min}$ at 50 $\mathrm{W}$ and $10 \mathrm{~min}$ at $100 \mathrm{~W}$ ), after which five 4-min intervals at a work rate corresponding to $85 \%$ of each subject's maximal oxygen uptake were performed. Each high-intensity interval was interspersed with 3 min of low-intensity cycling at $100 \mathrm{~W}$. During cycling, blood samples were taken after warm-up and after the third and fifth intervals. Immediately after the last interval $(<30 \mathrm{~s})$, a third muscle biopsy was taken off the cycle ergometer. After the biopsy was collected, subjects continued to cycle for an additional $10 \mathrm{~min}$ at $100 \mathrm{~W}$, which was then followed by $5 \mathrm{~min}$ of rest. Next, the subjects were seated in the leg press machine and performed three warm-up sets of 10 repetitions at $\sim 10, \sim 30$, and $\sim 60 \% 1 \mathrm{RM}$ with $3 \mathrm{~min}$ of rest between each set. Thereafter, the subjects performed 10 sets of heavy-resistance exercise for which the load and number of repetitions were determined during the last pretest. The subjects were to perform four sets of $8-10$ repetitions at $\sim 80 \% 1 \mathrm{RM}$, four sets of $10-12$ repetitions at $\sim 70 \%$ $1 \mathrm{RM}$, and finally two sets to volitional fatigue at $\sim 60 \% 1 \mathrm{RM}$, with 3 min of recovery allowed between each set. Time under tension was recorded for each set during the first trial and was used to match, as closely as possible, the repetition speed in each set during the second trial (Table 1). In the $\mathrm{R}$ trial, the cycling was replaced by rest, with blood and tissue sampling performed at the same time points as in the ER trial. During resistance exercise, blood was collected prior to warm-up and following the 3rd, 7th, 10th, and finally the 13th and last set.

In both trials, immediately after resistance exercise a fourth muscle biopsy was taken, and after that, two additional biopsies were collected 90 and 180 min post-resistance exercise. Blood was collected 15 and $30 \mathrm{~min}$ into recovery, after which sampling continued at 30-min intervals throughout the remainder of the trial. Biopsy sampling was alternated between legs throughout the two trials, beginning with the right leg in the first trial. A total of 12 biopsies were collected from each subject and for each biopsy, a new incision was made $\sim 2-3$ $\mathrm{cm}$ proximal to the previous one. After biopsy collection, samples were immediately blotted free of blood, frozen in liquid nitrogen, and stored at $-80^{\circ} \mathrm{C}$ for later analysis.

Tissue processing. Muscle samples were freeze-dried and thoroughly dissected clean from blood and connective tissue under a light microscope (Carl Zeiss MicroImaging, Jena, Germany), leaving only very small fiber bundles intact. The fiber bundles were then extensively mixed, resulting in a highly homogenous sample pool free of nonmuscle contaminants. This mixed sample was then split into aliquots for each subsequent analysis.

Immunoblot analysis. Cleaned muscle samples were homogenized in ice-cold buffer $(80 \mu \mathrm{l} / \mathrm{mg}$ dry wt) containing $2 \mathrm{mM}$ HEPES ( $\mathrm{pH}$ 7.4), $1 \mathrm{mM}$ EDTA, $5 \mathrm{mM}$ EGTA, $10 \mathrm{mM} \mathrm{MgCl} 2,50 \mathrm{mM} \beta$-glycerophosphate, $1 \%$ Triton $\mathrm{X}-100,1 \mathrm{mM} \mathrm{Na} \mathrm{VO}_{4}, 2 \mathrm{mM}$ dithiothreitol (DTT), $1 \%$ phosphatase inhibitor cocktail (Sigma P-2850), and 1\% (vol/vol) Halt Protease Inhibitor Cocktail (Thermo Scientific, Rockford, IL). Homogenates were then cleared by centrifugation at 10,000 $g$ for $10 \mathrm{~min}$ at $4^{\circ} \mathrm{C}$, and the resulting supernatant was stored at $-80^{\circ} \mathrm{C}$.

Protein concentrations were determined in aliquots of supernatant diluted 1:10 in distilled water using the Pierce $660 \mathrm{~nm}$ protein assay (Thermo Scientific). Samples were diluted in Laemmli sample buffer (Bio-Rad Laboratories, Richmond, CA) and homogenizing buffer to obtain a final protein concentration of $1.0 \mu \mathrm{g} / \mu \mathrm{l}$. Following dilution, all samples were heated at $95^{\circ} \mathrm{C}$ for $5 \mathrm{~min}$ to denature proteins present in the supernatant. Samples were then kept at $-20^{\circ} \mathrm{C}$ until further analysis.

For protein separation, samples containing $20 \mu \mathrm{g}$ of protein were loaded on Criterion TGX gradient gels (4-20\% acrylamide, Bio-Rad Laboratories), and electrophoresis was performed on ice at $250 \mathrm{~V}$ for $40 \mathrm{~min}$. Next, gels were equilibrated in transfer buffer $(25 \mathrm{mM}$ Tris base, $192 \mathrm{mM}$ glycine, and $10 \%$ methanol) for $30 \mathrm{~min}$, after which proteins were transferred to polyvinylidene difluoride membranes (Bio-Rad Laboratories) at a constant current of $300 \mathrm{~mA}$ for $3 \mathrm{~h}$ at $4^{\circ} \mathrm{C}$. To confirm equal loading after transfer, membranes were stained with a MemCode Reversible Protein Stain Kit (Thermo Scientific) (1). For each set of target proteins, all samples from each subject were loaded on the same gel, and all gels were run simultaneously.

Membranes were blocked for $1 \mathrm{~h}$ at room temperature in Trisbuffered saline (TBS; $20 \mathrm{mM}$ Tris base, $137 \mathrm{mM} \mathrm{NaCl}, \mathrm{pH}$ 7.6) containing $5 \%$ nonfat dry milk and $0.1 \%$ Tween 20 . After blocking, membranes were incubated overnight with commercially available primary antibodies diluted in TBS supplemented with $0.1 \%$ Tween 20 containing $2.5 \%$ nonfat dry milk (TBS-TM). Following incubation with these primary antibodies, membranes were washed with TBS-TM and incubated for $1 \mathrm{~h}$ at room temperature with secondary antibodies conjugated with horseradish peroxidase. Next, the membranes were washed with TBS-TM $(2 \times 1 \mathrm{~min}, 3 \times 10 \mathrm{~min})$ followed by four additional washes with TBS for 5 min each. Finally, membranes with the antibodies bound to the target proteins were visualized by chemiluminescent detection on a Molecular Imager ChemiDoc XRS system, and the bands were analyzed using the contour tool in the Quantity One v. 4.6.3 software (Bio-Rad Laboratories). To standard-

Table 1. Details of the performed resistance exercise

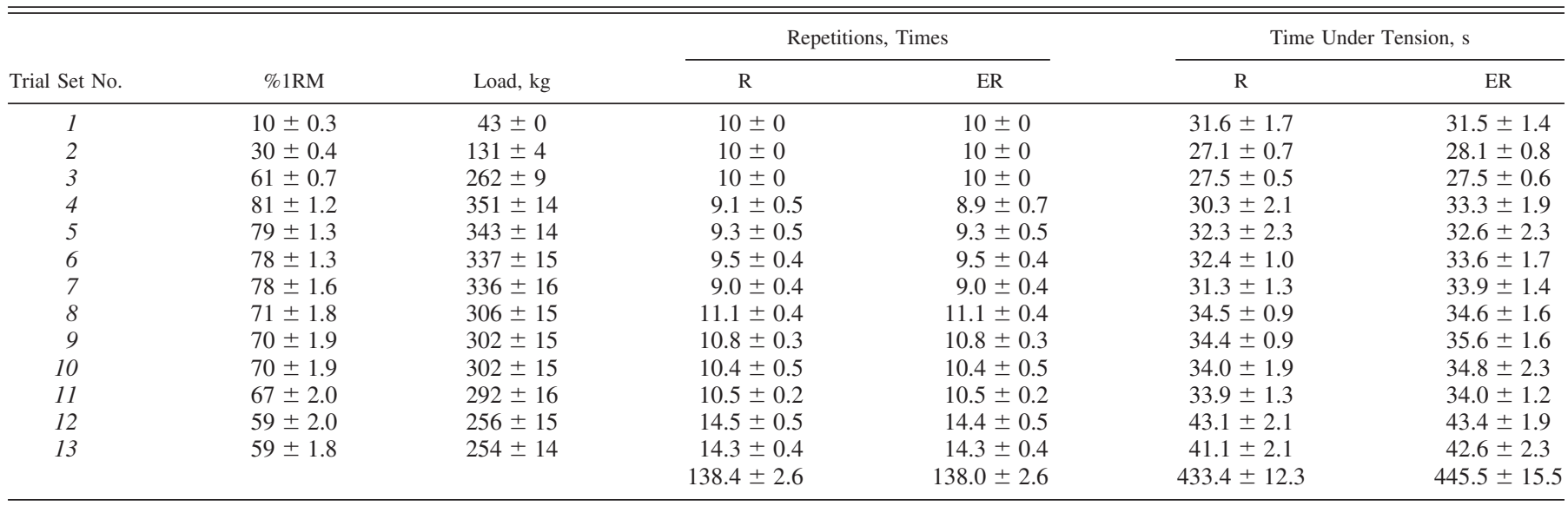

Values are presented as means \pm SE for 8 subjects. R, resistance exercise only; ER, interval cycling followed by resistance exercise; 1RM, one-repetition maximum. 
ize the immunoblotting procedure, prior to blocking, membranes were cut and assembled so that for each target protein all membranes with samples from each subject would be exposed to the same conditions. Following image capture of phosphorylated proteins, membranes were stripped of the phosphospecific antibodies, using Restore Western Blot Stripping Buffer (Thermo Scientific), for $30 \mathrm{~min}$ at $37^{\circ} \mathrm{C}$, after which the membranes were reprobed with primary antibodies for each respective total protein, as described above. All phosphoproteins were normalized to their corresponding total protein. When only total protein was measured, values were normalized against the total protein stain at $\sim 95 \mathrm{kDa}$ obtained with the MemCode kit.

Immunoprecipitation. To measure kinase activity and protein-protein interactions, immunoprecipitations (IP) of the target proteins were carried out on tissue samples homogenized in ice-cold IP lysis buffer containing $50 \mathrm{mM}$ HEPES (pH 7.5), $0.1 \mathrm{mM}$ EGTA, 1 mM EDTA, $1 \%$ (vol/vol) Triton $\mathrm{X}-100,50 \mathrm{mM} \mathrm{NaF}, 5 \mathrm{mM}$ sodium pyrophosphate, $1 \mathrm{mM} \mathrm{Na} \mathrm{VO}_{4}, 0.27 \mathrm{M}$ sucrose, $0.1 \%$ (vol/vol) $\beta$-mercaptoethanol $(\beta \mathrm{ME})$, and $1 \%(\mathrm{vol} / \mathrm{vol})$ Halt Protease Inhibitor Cocktail (Thermo Scientific). Following homogenization, samples were centrifuged at $10,000 \mathrm{~g}$ for $10 \mathrm{~min}$ at $4^{\circ} \mathrm{C}$, after which serial immunoprecipitations for the different target proteins were performed on the same supernatant. The choice to perform serial instead of separate IPs was due to limited amounts of tissue. For each sample, the first IP was performed on $750 \mu \mathrm{g}$ of protein, which was incubated with saturating amounts $(7.2 \mu \mathrm{g})$ of rabbit anti-S6K1 antibody and $10 \mu \mathrm{l}$ of protein G-Sepharose beads (GE Healthcare, Uppsala, Sweden) for $3 \mathrm{~h}$ at $4{ }^{\circ} \mathrm{C}$ on a rotating platform. After incubation, the beads containing the immune complexes were spun down, and the post-IP supernatant was divided into three aliquots. Two aliquots of $225 \mu \mathrm{g}$ of protein each were incubated with $4 \mu \mathrm{g}$ of AMPK $\alpha 1$ and AMPK $\alpha 2$ antibodies, respectively, and $10 \mu \mathrm{l}$ of protein G-Sepharose beads. The AMPK IP samples were combined with $800 \mu \mathrm{l}$ of AMPK lysis buffer [50 mM Tris. $\mathrm{HCl}(\mathrm{pH} 7.25), 150 \mathrm{mM} \mathrm{NaCl}, 50 \mathrm{mM} \mathrm{NaF}, 5 \mathrm{mM}$ sodium pyrophosphate, $1 \mathrm{mM}$ EDTA, $1 \mathrm{mM}$ EGTA, $1 \mathrm{mM}$ DTT, $1 \%$ (vol/vol) Triton X-100, and 1\% (vol/vol) Halt Protease Inhibitor Cocktail] to adjust for the slightly higher $\mathrm{pH}$ in the IP lysis buffer. The third aliquot of $175 \mu \mathrm{g}$ of protein was incubated with $1 \mu \mathrm{g}$ of goat anti-TSC1 antibody and $10 \mu \mathrm{l}$ of protein G magnetic beads (Thermo Scientific). AMPK and TSC1 IPs were incubated over night at $4^{\circ} \mathrm{C}$ on a rotating platform. Following IP, the beads with the S6K1 and AMPK immune complexes were washed twice in their respective high-salt lysis buffer (i.e., IP lysis buffer and AMPK lysis buffer; both with $0.5 \mathrm{M} \mathrm{NaCl}$ ) and once in kinase-specific assay buffer (see Kinase assays). Following incubation, IPs of TSC1 were washed four times in IP lysis buffer, after which the beads were combined with $1 \times$ LSB, boiled for $5 \mathrm{~min}$, and immunoblotted for TSC 1 and TSC 2 as described above. The amount of TSC2 was normalized against the amount of $\mathrm{TSC} 1$, i.e., the target protein in the immunoprecipitate.

Kinase assays. Following the last wash in kinase specific assay buffer (S6K1, $50 \mathrm{mM}$ Tris. $\mathrm{HCl}$ at $\mathrm{pH} 7.5,0.03 \%$ BrijL23, 0.1\% $\beta \mathrm{ME}$, AMPK, $50 \mathrm{mM}$ HEPES at pH 7.4, 1 mM DTT, 0.03\% BrijL23), the beads from each sample were suspended in assay buffer and divided into three assays of $20 \mu \mathrm{l}$ each. Two of the assays were run with a kinase-specific substrate, and the third assay was run without the substrate, thus serving as a blank. Kinase assays were initiated by the addition of $30 \mu \mathrm{l}$ of a hot (radiolabeled) kinase-specific reaction mix every $20 \mathrm{~s}$ and terminated at 20-s intervals by the addition of $50 \mu \mathrm{l}$ of phosphoric acid $(1 \% \mathrm{vol} / \mathrm{vol})$ to each assay. For the S6K1 activity assay, the final reaction mix $(50 \mu \mathrm{l})$ consisted of $100 \mu \mathrm{M}$ ATP, 10 $\mathrm{mM} \mathrm{MgCl} 2,{ }^{32} \gamma$-ATP (specific activity $\sim 2.5 \times 10^{6} \mathrm{cpm} / \mathrm{nmol}$ ), 30 $\mu \mathrm{M}$ synthetic S6K1 substrate (KRRRLASLR) and was carried out for $60 \mathrm{~min}$ at $30^{\circ} \mathrm{C}$. The AMPK activity assays were performed for 30 min at the same temperature and final volume, but in a reaction mix consisting of $200 \mu \mathrm{M}$ ATP, $200 \mu \mathrm{M}$ AMP, $5 \mathrm{mM} \mathrm{MgCl}_{2},{ }^{32} \gamma$-ATP (specific activity $\sim 0.2 \times 10^{6} \mathrm{cpm} / \mathrm{nmol}$ ) and $200 \mu \mathrm{M}$ synthetic AMPK substrate ("AMARA"; AMARRAASAAALARRR). After termination of the assay reactions, assays were spotted onto squares of p81 Whatman filter paper (GE Healthcare) and washed three times in phosphoric acid and once in acetone. When the p81 squares had dried, they were immersed in scintillation fluid (FilterSafe; Zinsser Analytic, Frankfurt, Germany) and counted on a liquid scintillation counter (Beckman Coulter, Bromma, Sweden). The average values from the duplicate assays with substrate were corrected for background noise by subtraction of the blank (no substrate) and values were expressed as picomoles per minute per milligram.

Antibodies. For immunoblotting, primary antibodies against Akt (Ser ${ }^{473}$, no. 9271; total, no. 9272), PRAS40 ( $\mathrm{Thr}^{246}$, no. 2997; total, no. 2691), TSC1 (total, no. 6935), TSC2 (Thr ${ }^{1387}$, no. 5584; total, no. 3635), mTOR ( $\mathrm{Ser}^{2448}$, no. 2971; total, no. 2983), S6K1 (Thr ${ }^{389}$, no. 9234; total no. 2708), 4E-BP1 (Thr ${ }^{37 / 46}$, no. 2855 ; total, no. 9644), eEF2 (Thr ${ }^{56}$, no. 2331; total, no. 2332), raptor (Ser ${ }^{792}$, no. 2083), and AMPK (Thr ${ }^{172}$, no. 4188; total, no. 2532) were purchased from Cell Signaling Technology (Beverly, MA). Primary total raptor (no. 09217) antibody was purchased from Merck Millipore (Billerica, MA), and the antibody against muscle atrophy F-box (MAFbx; no. 92281) was purchased from Abcam (Cambridge, UK). Total muscle RING finger 1 (MuRF1; no. sc-32920) antibody was purchased from Santa Cruz Biotechnology (Heidelberg, Germany). Validation of MuRF1 and MAFbx antibodies is shown in Fig. 8.

All primary antibodies were diluted 1:1,000 except for phosphoeEF2 and total raptor, which were diluted 1:5,000 and 1:2,000, respectively. Secondary anti-rabbit (no. 7074) and anti-mouse (no. 7076) antibodies $(1: 10,000)$ were purchased from Cell Signaling Technology and secondary anti-goat (no. ab7132, 1:10,000) antibody was purchased from Abcam.

For immunoprecipitation, S6K1 (no. sc-230) and TSC1 (no. sc12082) antibodies were purchased from Santa Cruz Biotechnology. Isoform-specific antibodies against AMPK $\alpha 1$ and $-\alpha 2$ were produced by GL Biochem (Shanghai, China), based on antigen sequences TSPPDSFLDDHHLTR and CMDDSAMHIPPGLKPH, respectively.

$R N A$ extraction and quantitative RT-PCR. Total RNA was extracted from $\sim 3 \mathrm{mg}$ of lyophilized and cleaned tissue, which was homogenized in PureZOL RNA isolation reagent (Bio-Rad Laboratories) according to the manufacturer's instructions. The concentration and purity of the RNA were determined by spectrophotometry, and 2 $\mu \mathrm{g}$ of RNA was used for reverse transcription of $40 \mu \mathrm{l}$ of cDNA with an iScript cDNA Synthesis Kit (Bio-Rad Laboratories). The primers for the specific genes analyzed here have been presented in previous work from our laboratory (9). The concentration of cDNA, annealing temperature, and PCR cycle protocol were determined for each primer pair to ensure optimal conditions for amplification. Samples were run in triplicate, and all samples from each subject were run on the same plate to allow direct relative comparisons. qRT-PCR amplification mixtures $(25 \mu \mathrm{l})$ contained $12.5 \mu \mathrm{l}$ of $2 \times$ SYBR Green Supermix (Bio-Rad Laboratoies), $0.5 \mu 110 \mu \mathrm{M}$ forward and reverse primers, respectively, and $11.5 \mu \mathrm{l}$ of template cDNA in RNase-free water. qRT-PCR was performed with a Bio-Rad iCycler (Bio-Rad Laboratories), and relative changes in mRNA levels were analyzed by the $\Delta \mathrm{C}_{\mathrm{T}}$ method, with GAPDH used as the reference gene. The reliability of GAPDH mRNA as an internal control was validated by the $2^{-\Delta \mathrm{C}^{\prime}}{ }_{\mathrm{T}}$ method, where $\Delta \mathrm{C}^{\prime}{ }_{\mathrm{T}}=\mathrm{C}_{\mathrm{T}}$ time $\times-\mathrm{C}_{\mathrm{T}}$ time o.

Plasma analysis. Blood samples (4 ml) were centrifuged at 9,000 $\mathrm{g}$ at $4^{\circ} \mathrm{C}$ for $3 \mathrm{~min}$, and the plasma obtained was stored at $-20^{\circ} \mathrm{C}$. Plasma analyses of glucose and lactate concentrations were performed as described by Bergmeyer (5), and plasma insulin levels were determined using an ELISA kit (Mercodia, Uppsala, Sweden) in accordance with the manufacturer's instructions.

Muscle glycogen. Muscle glycogen was determined in $2-3 \mathrm{mg}$ of dry muscle according to Leighton et al. (33). Briefly, each sample was incubated in $150 \mu \mathrm{l}$ of $1 \mathrm{M} \mathrm{KOH}$ for $15 \mathrm{~min}$ at $70^{\circ} \mathrm{C}$, after which the digest was transferred to new tubes and the $\mathrm{pH}$ adjusted to 4.8 with glacial acetic acid. Following acidification, 0.1 M NaAc-buffer with amyloglycosidase (Roche Diagnostics Scandinavia, Bromma, Sweden) was added to each sample, and enzymatic glycogen degradation 

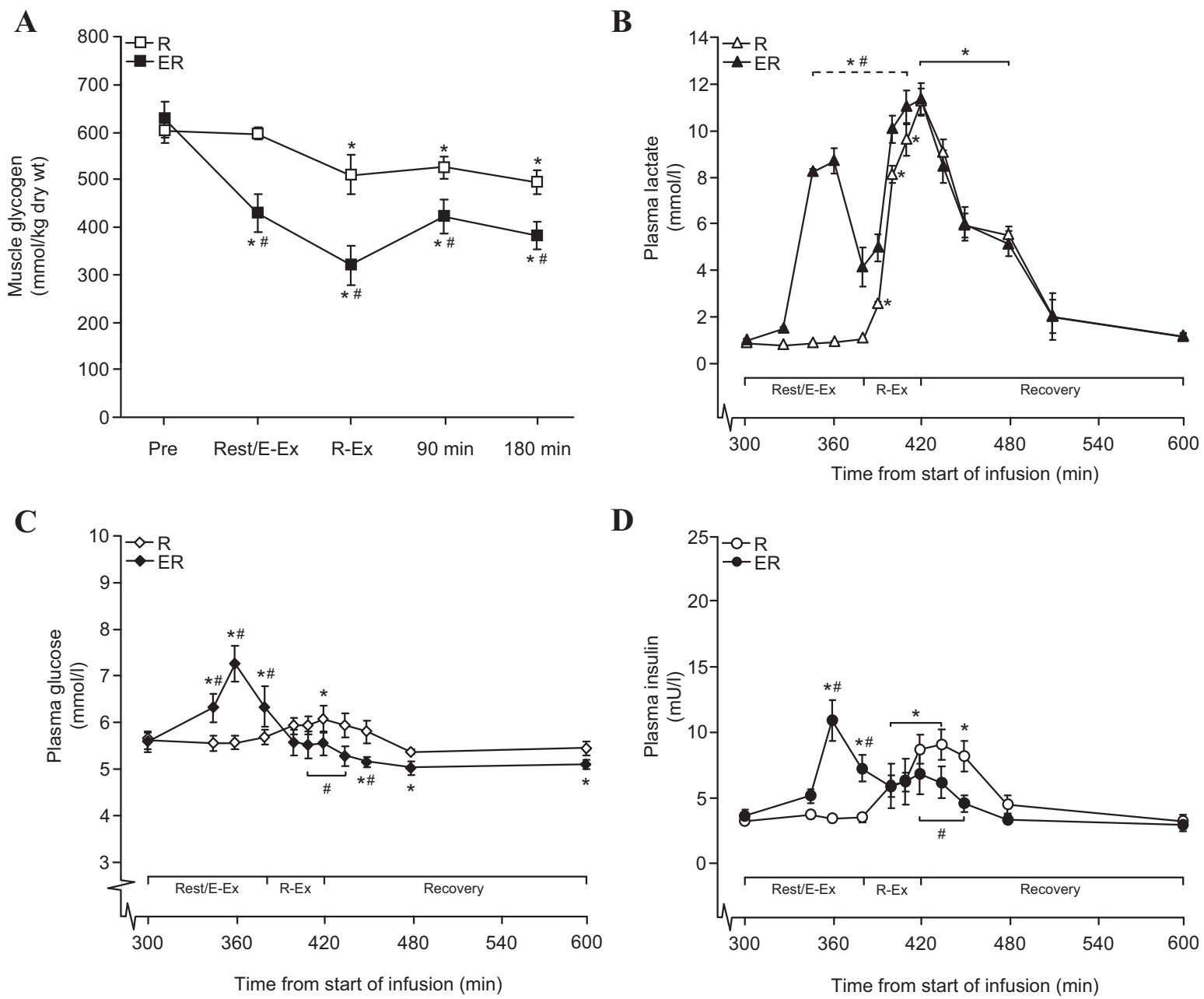

Fig. 2. Concentrations of muscle glycogen $(A)$, plasma lactate $(B)$, plasma glucose $(C)$, and plasma insulin $(D)$ during the two trials. For $B$, symbols above the dashed line represent the ER trial; those above the continuous line represent both trials. Values are presented as means \pm SE for 8 subjects. $* P<0.05$ vs. Rest; $\# P<0.05$ vs. $\mathrm{R}$ trial.

was performed for $2 \mathrm{~h}$ at $40^{\circ} \mathrm{C}$. The resulting glucose concentration was determined as described by Bergmyer (5), and glycogen levels were expressed as micromoles per kilogram of dry muscle.

Stable-isotope enrichment analysis. For plasma enrichment analysis, $200 \mu \mathrm{l}$ of each plasma sample was combined with $100 \mu \mathrm{l}$ of internal standard (L-[ring- $\left.{ }^{13} \mathrm{C}_{9}\right]$ phenylalanine, $\left.50 \mu \mathrm{mol} / \mathrm{l}\right)$ and $500 \mu \mathrm{l}$ of acetic acid $(50 \%)$ before being passed through a cation exchange resin column (Dowex AG 50W-X8, Bio-Rad). Amino acids were then eluted with $2 \mathrm{ml}$ of $2 \mathrm{M} \mathrm{NaOH}$, dried under a stream of $\mathrm{N}_{2}$, and derivatized by the addition of $50 \mu \mathrm{l}$ of $N$-methyl-N-(tert-butyldimethylsilyl)-trifluoroacetamide and acetonitrile $(1: 1)$ and heated at $70^{\circ} \mathrm{C}$ for $1 \mathrm{~h}$. Plasma enrichment as well as enrichment of the internal standard were measured using gas chromatography-tandem mass spectrometry (GC-MS-MS; Tracer GC Ultra-TSQ Quantum; Thermo Scientific, Palo Alto, CA) with electron impact ionization and selective ion monitoring for 336, 342, and $345 \mathrm{~m} / \mathrm{z}$.

For muscle enrichment analysis, $\sim 7 \mathrm{mg}$ of dry muscle tissue was combined with $100 \mu \mathrm{l}$ of internal standard (L-[ring${ }^{13} \mathrm{C}_{9}$ ]phenylalanine, $\left.5 \mu \mathrm{mol} / \mathrm{l}\right)$, after which samples were pelleted and extracted twice with $500 \mu \mathrm{l}$ of $2 \%$ perchloric acid. To determine intracellular enrichment of free phenylalanine, supernatants were combined and processed as described above for plasma enrichment. The remaining pellet was washed twice with $70 \%$ ethanol and then hydrolyzed overnight in $1 \mathrm{ml}$ of $6 \mathrm{M} \mathrm{HCl}$ heated to $110^{\circ} \mathrm{C}$. The hydrolyzed proteins were then dissolved in $500 \mu$ l of acetic acid
(50\%) and passed through a cation exchange column. To determine protein-bound phenylalanine enrichment, the purified pellet-derived amino acids were converted to their $N$-acetyl- $n$-propyl amino acid esters and analyzed by gas chromatography-combustion-isotope ratio mass spectrometry (GC-C-IRMS; Hewlett Packard 5890-Finnigan GC

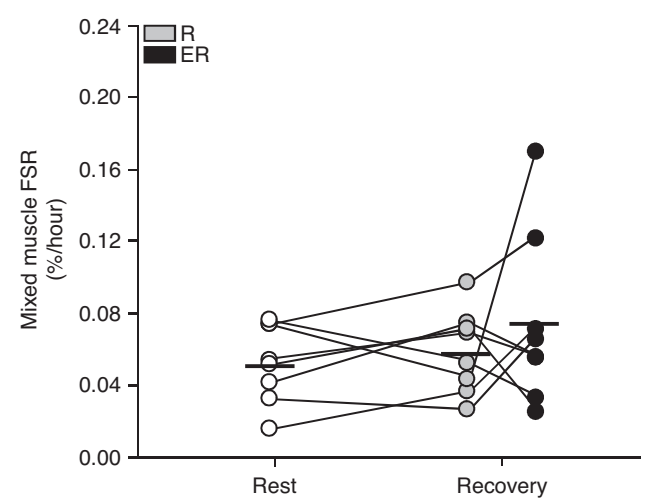

Fig. 3. Individual values for mixed-muscle fractional synthesis rate (FSR) during $180 \mathrm{~min}$ of rest in the first trial and during $180 \mathrm{~min}$ of recovery in both trials. Individual values are presented for 8 subjects. Mean FSR values are indicated by horizontal lines. 
combustion III-Finnigan Deltaplus; Finnigan MAT, Bremen, Germany).

Calculations for mixed-muscle fractional synthetic rate. Mixed muscle protein fractional synthesis rate (FSR) was calculated using the standard precursor-product method:

$$
\mathrm{FSR}=\Delta E_{p \text { phe }} /\left(E_{i c} \text { phe } \times t\right) \times 100
$$

where $\Delta E_{p}$ phe is the difference in protein-bound phenylalanine enrichment between two biopsies, $E_{i c}$ phe is the mean intracellular phenylalanine enrichment of two biopsies, and $t$ is the time period for tracer incorporation between biopsies in hours multiplied by 100 to express FSR in percent per hour $(\% / \mathrm{h})$.

Statistical analyses. Parametric statistical procedures were employed to calculate the means and standard errors of the mean (SE). Unless indicated otherwise, the values presented in the text are means \pm SE. A two-way (trial $\times$ time) repeated-measures ANOVA was used to compare changes in FSR, kinase activity, intracellular signaling, protein-protein interactions, gene and protein expression, muscle glycogen, and plasma variables. In case of a significant main effect or an interaction effect, a Fisher's least significant difference post hoc test was performed. For some positively skewed distributed variables, $\log$ transformation was performed before the formal analyses. For analysis of time under tension, a paired $t$-test was used. Statistical analyses were performed using STATISTICA v. 12.0 (StatSoft, Tulsa, OK). $P<0.05$ was considered statistically significant.

\section{RESULTS}

Physiological and metabolic parameters. In the resistance exercise protocol, the number of repetitions averaged $138 \pm$ 2.6 ( 7 subjects performed exactly the same number of repetitions in the 2 trials, and 1 subject performed 3 repetitions fewer in the ER trial). Total time under tension averaged $433 \pm 12 \mathrm{~s}$ and $446 \pm 16 \mathrm{~s}$ in the $\mathrm{R}$ and ER trials, with no difference between the two.

Muscle glycogen decreased by $30 \%(P<0.05)$ during the interval cycling and by an additional $25 \%(P<0.05)$ following resistance exercise in the ER trial. The reduction during resistance exercise in the $\mathrm{R}$ trial averaged $15 \%(P<0.05)$,
A
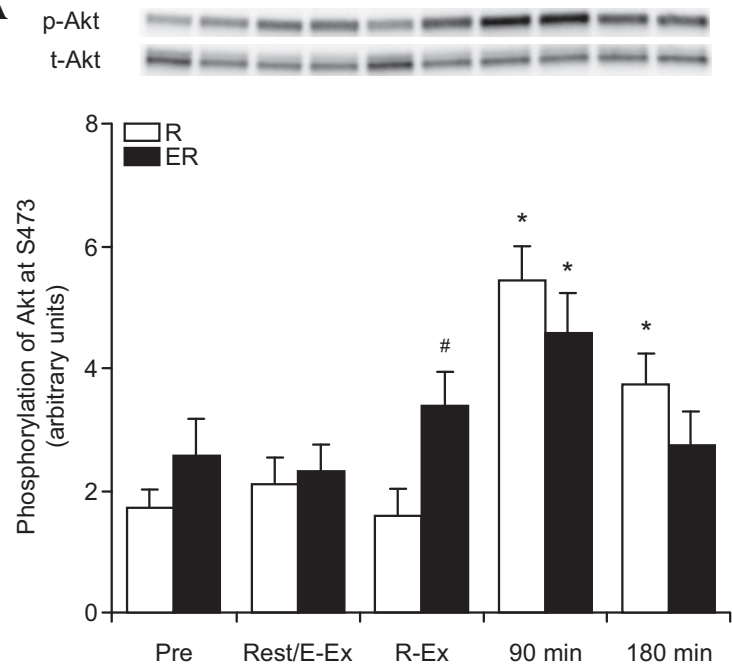

C
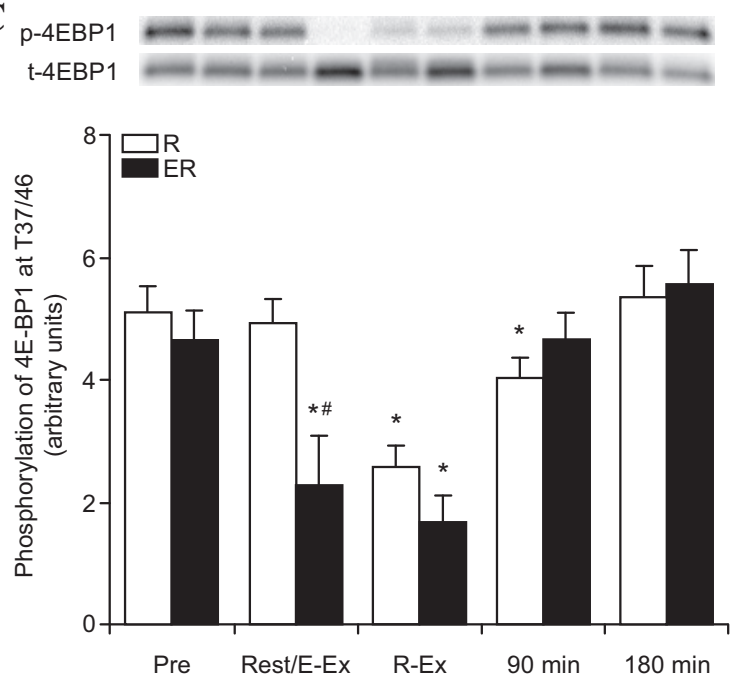

B
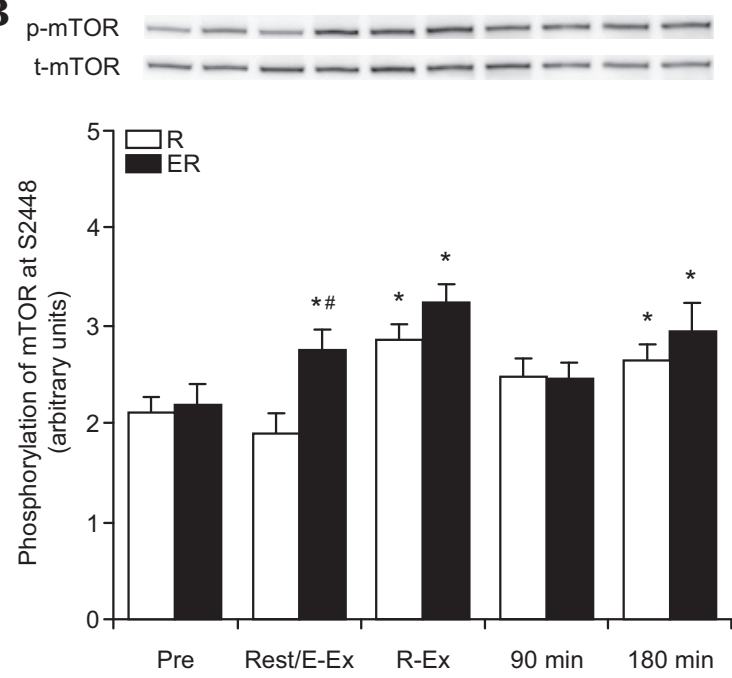

D
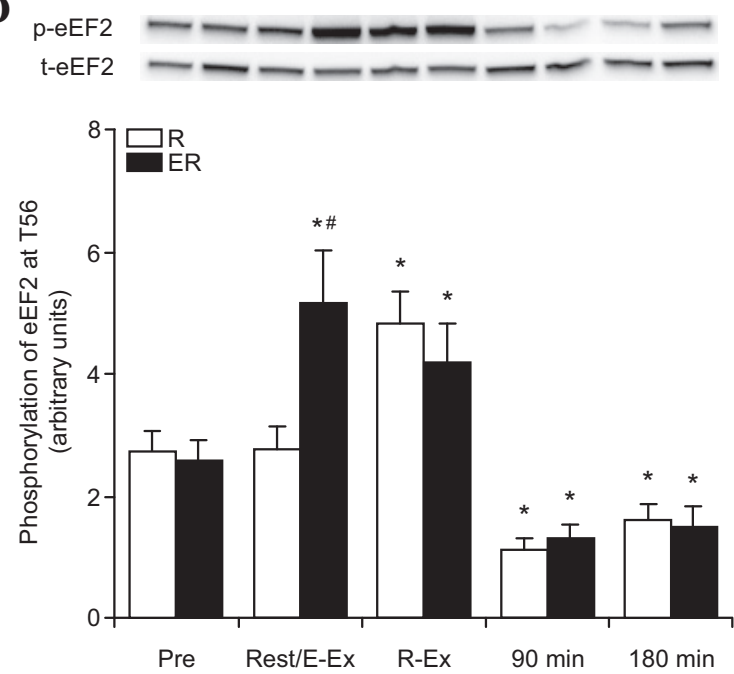

Fig. 4. Phosphorylation levels of Akt at $\operatorname{Ser}^{473}(A)$, mTOR at $\operatorname{Ser}^{2448}(B), 4 \mathrm{E}-\mathrm{PB} 1$ at $\mathrm{Thr}^{37 / 46}(C)$, and eEF2 at Thr ${ }^{56}(D)$ before and after exercise. Phosphorylation levels are normalized to corresponding total levels of each protein and presented as means \pm SE for 8 subjects. Representative bands are shown above each graph. Symbols above lines denote differences revealed by a post hoc test when a main effect was observed. Symbols without lines denote differences revealed by a post hoc test when an interaction effect was observed. $* P<0.05$ vs. Rest; $\# P<0.05$ vs. R trial. 
quantitatively similar as during the corresponding exercise in the ER trial (Fig. 2A).

The concentration of plasma lactate increased markedly during the interval cycling and was further elevated during the following resistance exercise. The rise in plasma lactate during resistance exercise in the $\mathrm{R}$ trial was similar to that during the corresponding exercise in the ER trial (Fig. 2B). Plasma glucose increased slightly in the $\mathrm{R}$ trial, reaching significantly higher levels immediately after resistance exercise. In the ER trial, glucose levels peaked immediately after interval cycling, after which levels dropped below baseline values during the end of recovery (Fig. 2C). Alterations in plasma levels of insulin essentially mimicked those of plasma glucose. In the $\mathrm{R}$ trial, insulin levels increased during resistance exercise and remained slightly elevated during the initial recovery period. In the ER trial, insulin levels increased after interval cycling but declined during the subsequent resistance exercise to similar levels as in the $\mathrm{R}$ trial. After the initial recovery period, insulin levels had returned to baseline values in both trials (Fig. 2D). Importantly, all values were well within the range for fasting levels of plasma insulin (12).

Intracellular enrichment and mixed muscle FSR. Resting FSR values were initially determined in both trials; however, the resting value was significantly higher in the second trial. We have no obvious explanation for this finding, but to overcome this problem we chose to present resting values from each subject's first trial. We believe that presenting values in this manner is comparable to that of other studies in which resting FSR was measured only in the first of two experiments $(18,49)$. As a result of the randomized and counterbalanced study design, four resting values were obtained during the $\mathrm{R}$ trial and another four during the ER trial.

Mean intracellular enrichment [tracer-to-tracee ratio (TTR)] during rest was $0.035 \pm 0.001$ and increased significantly $(P<$ $0.05)$ during recovery in both trials $(\mathrm{R}, 0.049 \pm 0.002$ vs. ER, $0.049 \pm 0.003$ ). FSR during $180 \mathrm{~min}$ of rest averaged $0.050 \pm$ $0.008 \% / \mathrm{h}$. Values during the 180 -min recovery period following exercise averaged $0.057 \pm 0.008 \% / \mathrm{h}$ in the $\mathrm{R}$ trial and
$0.074 \pm 0.017 \% / \mathrm{h}$ in the ER trial, with no difference between the two (Fig. 3).

Intracellular signaling, kinase activity, and protein-protein interactions. Phosphorylation of Akt at $\mathrm{Ser}^{473}$ was significantly higher immediately after resistance exercise in the ER trial compared with the $\mathrm{R}$ trial, even though there was no increase compared with preexercise in either trial. At 90 min postresistance exercise, Akt phosphorylation was elevated to a similar extent in both trials $(P<0.05)$, and at the 180 -min time point this elevation was maintained in the $\mathrm{R}$ trial but not in the ER trial (Fig. 4A). Phosphorylation of Pras40 at $\mathrm{Thr}^{246}$ increased $\sim 30$ and $40 \%$ compared with baseline values $(P<$ $0.05)$ at 90 and 180 min post-resistance exercise, respectively, without any difference between trials (data not shown).

Immediately after cycling, mTOR phosphorylation at the Ser $^{2448}$ residue increased significantly and was also higher than in the $\mathrm{R}$ trial $(P<0.05)$. After resistance exercise, phosphorylation of mTOR was elevated in the $\mathrm{R}$ trial compared with preexercise values and further elevated in the ER trial vs. after cycling $(P<0.05)$. Phosphorylation dropped at the $90-\mathrm{min}$ time point but was again significantly elevated 180 min postexercise $(P<0.05)$, with no difference between trials during recovery (Fig. $4 B$ ). Phosphorylation of $4 \mathrm{E}-\mathrm{BP} 1$ at $\mathrm{Thr}^{37 / 46}$ was repressed $\sim 50 \%$ after cycling compared with baseline values $(P<0.05)$. After resistance exercise, the reduced 4E-BP1 phosphorylation was maintained at the same level in the ER trial but was now accompanied by a similar reduction in the $\mathrm{R}$ trial $(P<0.05)$. In the $\mathrm{R}$ trial, at the 90 -min time point, 4E-BP1 phosphorylation remained significantly lower $(P<$ $0.05)$ compared with preexercise but not compared with the ER trial, despite returning to near baseline values. At $180 \mathrm{~min}$ post-resistance exercise, phosphorylation of 4E-BP1 had returned to preexercise levels in both trials (Fig. 4C). Phosphorylation of eEF2 at $\mathrm{Thr}^{56}$ increased $\sim 95 \%$ immediately after cycling $(P<0.05)$. After resistance exercise, this increase was maintained in the ER trial but was also evident in the $\mathrm{R}$ trial. In contrast, at the 90-min time point, phosphorylation of eEF2 was instead reduced by $\sim 55 \%$ compared with baseline $(P<$
A

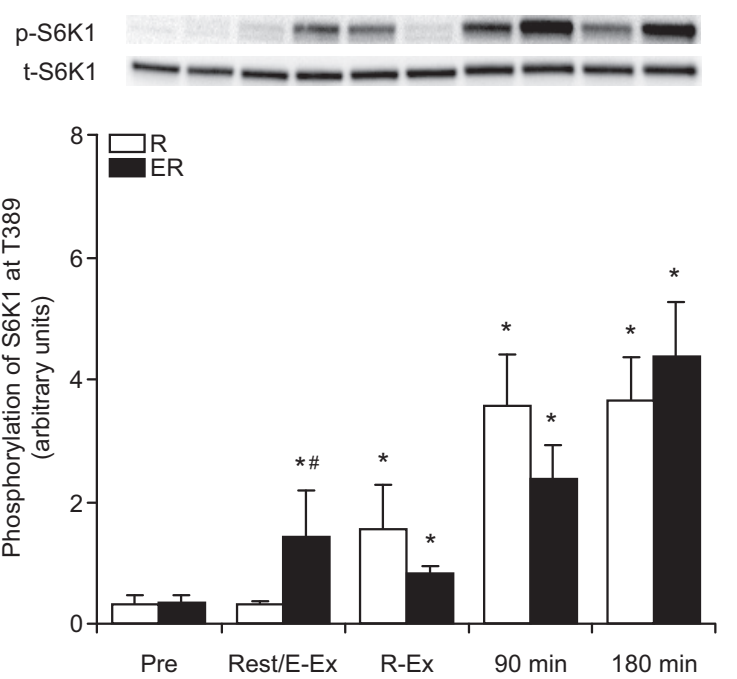

B

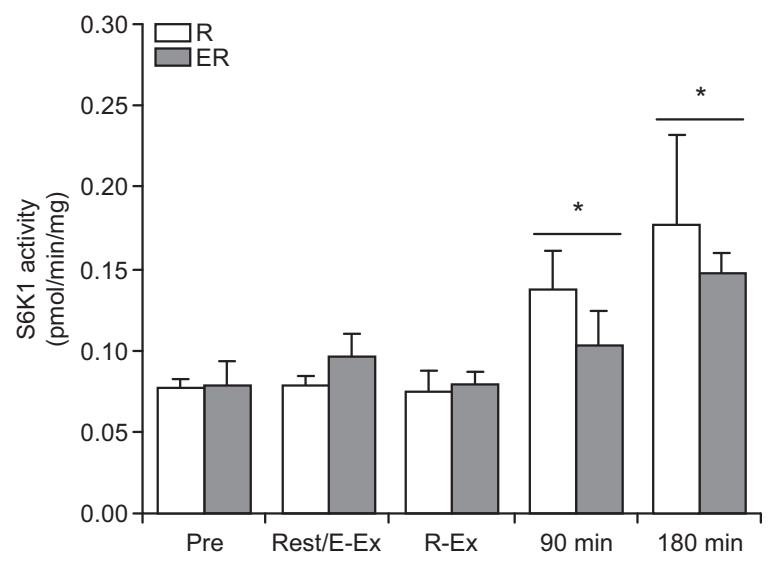

Fig. 5. Phosphorylation at $\mathrm{Thr}^{389}(A)$ and kinase activity of S6K1 $(B)$ before and after exercise. Phosphorylation levels are normalized to the total levels of S6K1. All values are presented as means \pm SE for 8 subjects. Representative bands are shown above the appropriate graph. Symbols above lines denote differences revealed by a post hoc test when a main effect was observed. Symbols without lines denote differences revealed by a post hoc test when an interaction effect was observed. ${ }^{*} P<0.05$ vs. Rest; $\# P<0.05$ vs. R trial. 
0.05 ), and this reduction was maintained at the 180-min time point. There was no difference between trials at any time point during recovery (Fig. 4D).

Immediately after cycling, $\mathrm{Thr}^{389}$ phosphorylation of S6K1 was increased approximately fivefold $(P<0.05)$ vs. baseline. Phosphorylation of S6K1 was elevated immediately after resistance exercise in both trials and continued to increase at both time points during recovery, reaching an $\sim 12$-fold increase at the 180-min time point compared with preexercise levels $(P<$ 0.05). There was no difference in S6K1 phosphorylation between trials at any time point during the recovery period after resistance exercise (Fig. 5A). The activity of S6K1 was unchanged after cycling in the ER trial as well as after resistance exercise in both trials. During recovery, the activity increased progressively, with a $55 \%$ increase at 90 $\min (P<0.05)$ followed by a $110 \%$ increase at $180 \mathrm{~min}$ $(P<0.05)$ after resistance exercise with no difference between the trials (Fig. 5B).

A

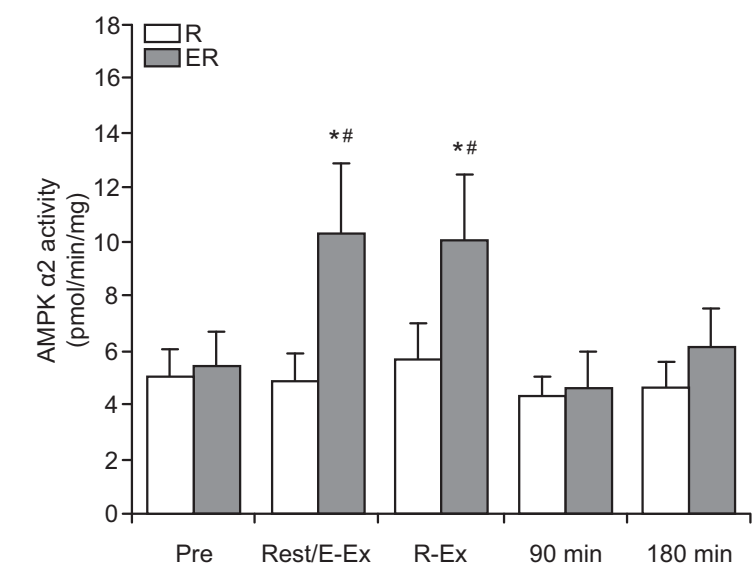

C

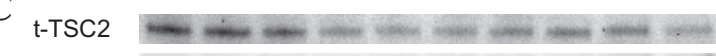

IP. $\mathrm{t}-\mathrm{TSC} 1$

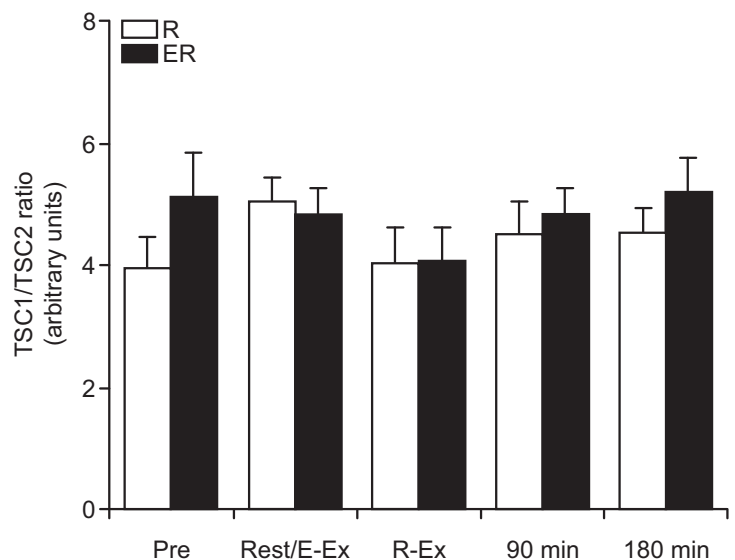

The kinase activity of AMPK $\alpha 1$ was unchanged at all time points in both trials (data not shown). In contrast, AMPK $\alpha 2$ activity increased $\sim 90 \%$ after cycling and remained elevated also after resistance exercise in the ER trial $(P<0.05)$. There was no change in $\mathrm{AMPK} \alpha 2$ activity at any time point during the $\mathrm{R}$ trial (Fig. 6A).

Phosphorylation of TSC2 at $\mathrm{Ser}^{1387}$ increased by $\sim 50 \%$ immediately after cycling in the ER trial, and a similar increase was seen after resistance exercise in both trials $(P<0.05$; Fig. $6 B)$. Protein-protein interactions between TSC1 and TSC2 were unchanged at all time points in both trials (Fig. 6C). Phosphorylation of raptor at $\mathrm{Ser}^{792}$ was unaffected by cycling but increased slightly immediately after resistance exercise in both trials $(P<0.05)$. During recovery, phosphorylation of raptor was maintained at 180 min after exercise compared with preexercise levels $(P<0.05)$ but without any difference between trials (Fig. $6 D$ ).

$m R N A$ and protein expression. Expression of MuRF1 mRNA was unchanged in the $\mathrm{R}$ trial at all time points but

B
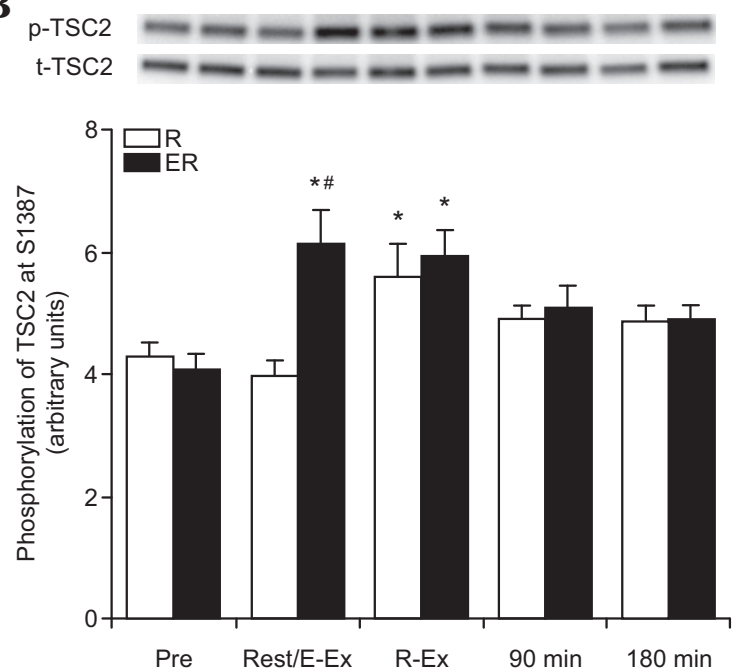

D
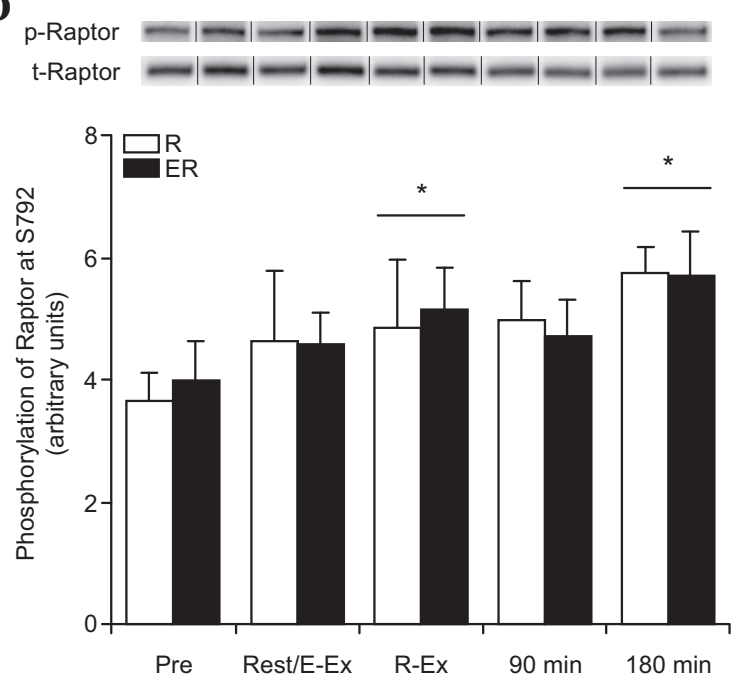

Fig. 6. Kinase activity of AMPK $\alpha 2(A)$, phosphorylation of TSC2 at $\operatorname{Ser}^{1387}(B)$, interaction between TSC1 and TSC2 $(C)$, and phosphorylation of raptor at Ser ${ }^{792}$ (D). TSC2 is normalized to the amount of TSC1 present in the immunoprecipitate. Phosphorylation levels are normalized to corresponding total levels of each protein and presented as means \pm SE for 8 subjects. Representative bands are shown above the appropriate graphs. For raptor only, bands were cut and repositioned to fit the graph. Symbols above lines denote differences revealed by a post hoc test when a main effect was observed. Symbols without lines denote differences revealed by a post hoc test when an interaction effect was observed. ${ }^{*} P<0.05$ vs. Rest; $\# P<0.05$ vs. R trial. 
increased 2.2- and 1.6-fold $(P<0.05)$ at 90 and 180 min after resistance exercise in the ER trial. Protein expression of MuRF1 did not change in the R trial but increased in the ER trial at 180 min during recovery by $\sim 15 \%$ compared with before exercise as well as compared with the R trial $(P<0.05)$. In contrast, at $180 \mathrm{~min}$ postexercise, mRNA expression of MAFbx decreased by $\sim 50 \%$ the $\mathrm{R}$ trial $(P<0.05)$, while it tended to increase at the same time point in the ER trial $(P<$ 0.065). Protein expression of MAFbx decreased slightly but significantly $(\sim 10 \%, P<0.05)$ at the 180 -min time point during recovery, with no difference between trials (Fig. 7).

\section{DISCUSSION}

The key finding of this study is that prior activation of AMPK by high-intensity endurance exercise does not inhibit resistance exercise-induced mTORC1 signaling during recov- ery. Furthermore, the combination of cycling and resistance exercise resulted in divergent expression patterns of the proteolytic ubiquitin ligases MuRF1 and MAFbx, implicating these targets as potential mediators of the proposed interference effect in response to concurrent exercise.

In contrast to our hypothesis, high-intensity endurance exercise performed prior to resistance exercise did not inhibit mTORC1 signaling during recovery. These findings expand on those of our previous study (2), in which we showed that resistance exercise-induced mTORC1 signaling was unaffected by the addition of continuous cycling after resistance exercise. However, in that study, we were unable to detect an increase in AMPK phosphorylation following either form of exercise, possibly due to the choice of exercise order (14) and/or the moderate intensity of the cycling protocol (52). In contrast, the experimental design and cycling protocol used here induced a
A

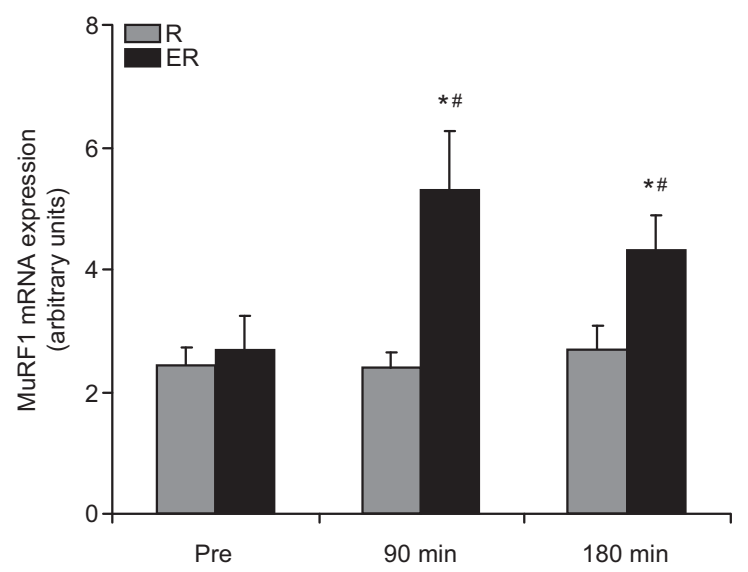

C

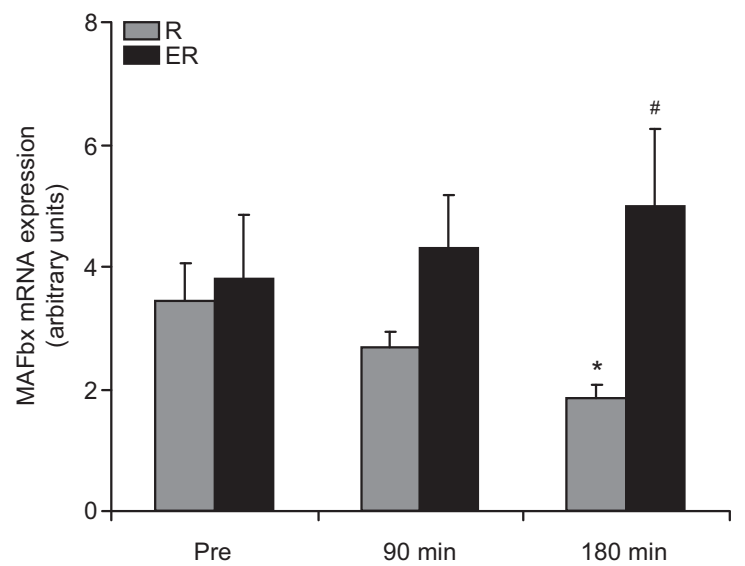

B

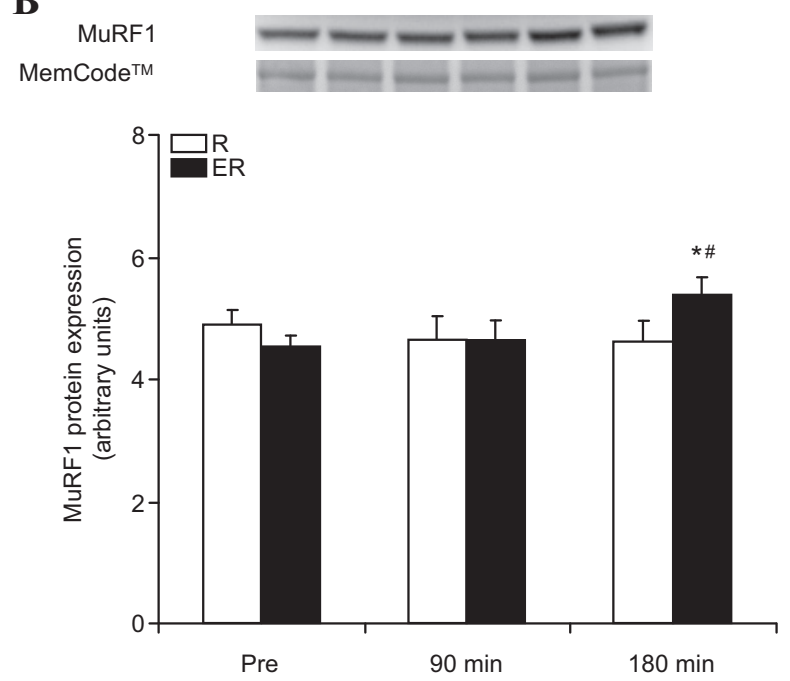

D
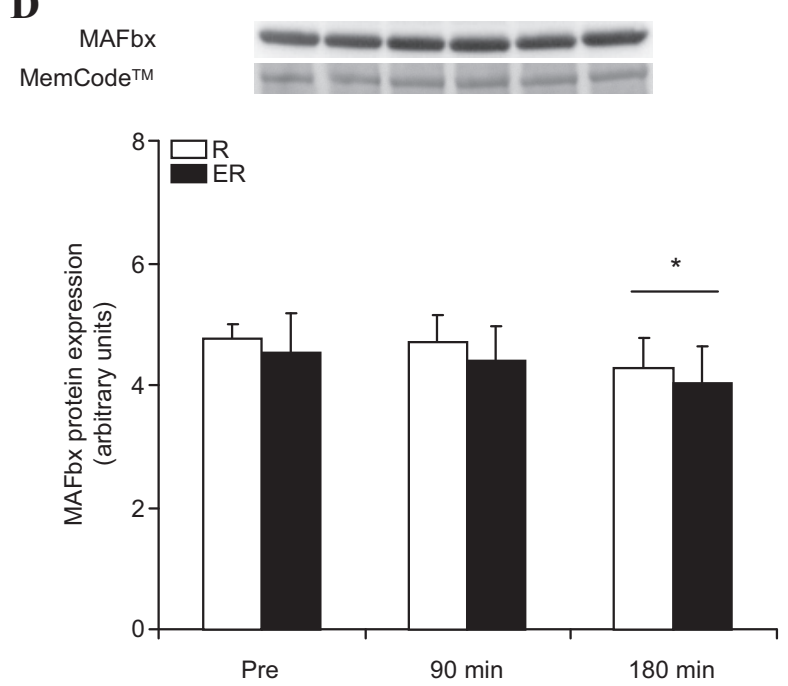

Fig. 7. Expression of MuRF1 mRNA $(A)$ and protein $(B)$ and of MAFbx mRNA $(C)$ and protein $(D)$ before and after exercise. Protein levels of MuRF1 and MAFbx were normalized to total protein levels obtained with the MemCode kit, and mRNA levels were normalized to GAPDH. All values are presented as means \pm SE for 8 subjects. Representative bands are shown above the appropriate graphs. Symbols above lines denote differences revealed by a post hoc test when a main effect was observed. Symbols without lines denote differences revealed by a post hoc test when an interaction effect was observed. $* P<0.05$ vs. Rest; $\# P<0.05$ vs. R trial. 

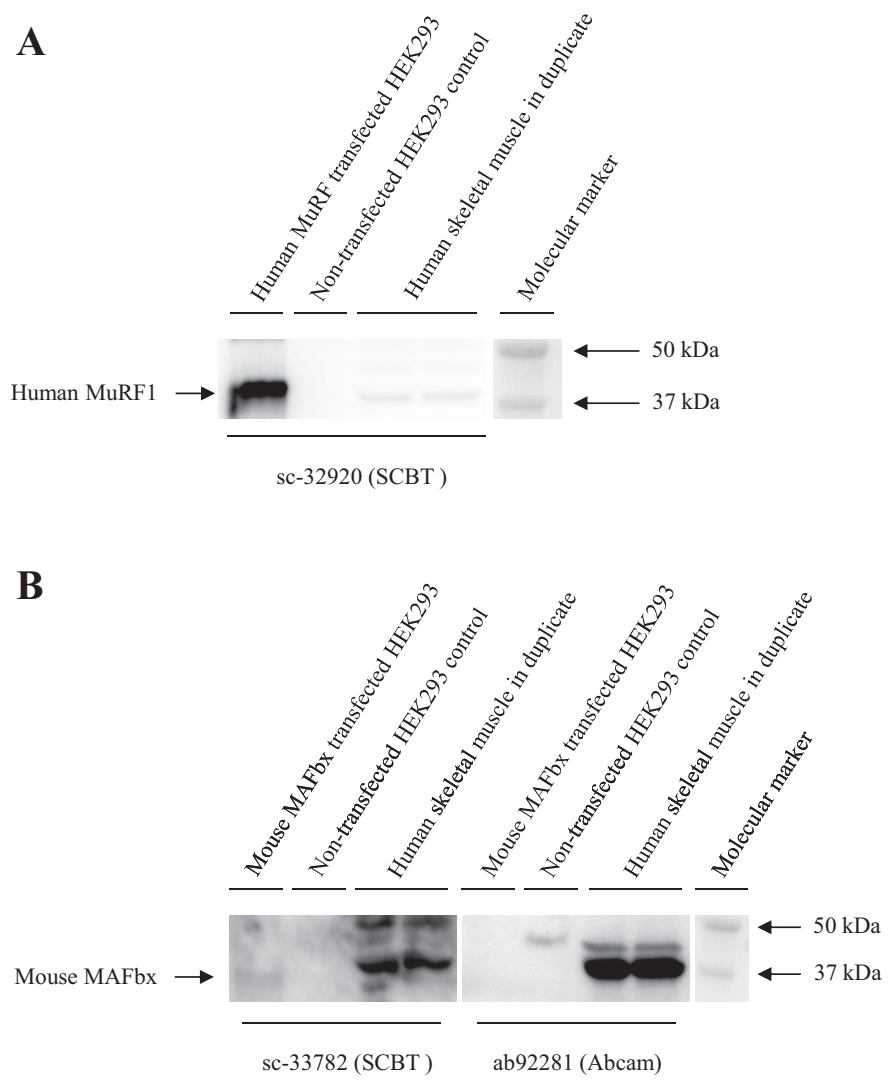

Fig. 8. Validation of Murf1 $(A)$ and MAFbx $(B)$ antibodies. Validation was carried out using HEK-293 cells transfected with human MURF1 protein (sc-32920) or mouse MAFbx protein (sc-121485). Nontransfected HEK-293 cells (sc-117752) were used as negative controls. All lysates were purchased from Santa Cruz Biotechnology (SCBT). A: MuRF1 was detected using a rabbit polyclonal anti-MuRF1 antibody (sc-32920, SCBT), which detected distinct bands of similar size $(\sim 40 \mathrm{kDa})$ in both the transfected cell lysate and the human muscle samples. No band was detected in the control lysate. $B$ : MAFbx was validated using a rabbit polyclonal anti-MAFbx antibody (sc33782, SCBT), which detected bands of similar size $(\sim 37-38 \mathrm{kDa})$ in both the mouse-transfected cells and the human muscle samples. No band was detected in the control lysate. Due to heavy background when using the sc-33782 antibody, a goat polyclonal anti-MAFbx antibody (ab92281, Abcam) was also evaluated. This antibody did not detect mouse MAFbx in the HEK-293 cells but did detect distinct bands in the human muscle samples. The sizes of these bands were identical to those detected by the sc-33782, which confirmed that the ab92281 antibody recognized human MAFbx. As the ab92281 antibody did not produce any background, it was chosen for the muscle analysis.

robust increase in AMPK $\alpha 2$ activity, which is in line with previous reports showing that AMPK $\alpha 2$ is activated in human muscle in response to endurance exercise $(20,52)$. The cycling-induced AMPK $\alpha 2$ activity remained elevated immediately after resistance exercise, whereas the activity of both AMPK isoforms was unaffected by single-mode resistance exercise. The lack of increase in $\alpha 2$ kinase activity in the $\mathrm{R}$ trial is in contrast to the findings of Dreyer et al. (19), who noted a $75 \%$ rise in AMPK $\alpha 2$ activity immediately after resistance exercise. Although the reason for this discrepancy is not readily obvious, it may be related to the training status of our subjects, who were well accustomed to resistance exercise, in contrast to the subjects in the Dreyer study (19). In support of this notion, Coffey et al. (16) showed unaltered AMPK phosphorylation immediately after resistance exercise in strength-trained men.
Several mechanisms have been suggested by which AMPK could inhibit mTORC1 signaling. First, AMPK has been shown to phosphorylate TSC2 (29), thereby stimulating its GAP activity toward Rheb (27), the essential activator of mTORC1 (45). As expected, phosphorylation of TSC2 was elevated in response to both modes of exercise in the ER trial, mimicking the activity pattern of AMPK. However, resistance exercise alone also elevated TSC2 phosphorylation, without a concomitant increase in AMPK activity. The reason for this divergence is unclear but suggests that in human skeletal muscle TSC2 may be targeted by additional kinases other than AMPK. The regulatory role of TSC2 may also be dependent on its interaction with TSC1 (28). Pharmacological and exerciseinduced activation of AMPK has been shown to increase TSC complex assembly in myoblasts (50) and adult muscle (51) of mice but not in rat skeletal muscle (43). We could not detect any change in the association between TSC1 and TCS2 at any time point in either trial despite the large increase in AMPK activity, which is in line with the results by Pruznak et al. (43).

A second mechanism of AMPK-mediated inhibition of mTORC1 involves phosphorylation of raptor at the $\mathrm{Ser}^{792}$ residue, which in cell culture and in vivo models of rodent muscle results in decreased phosphorylation of $\mathrm{S} 6 \mathrm{~K} 1$ and $4 \mathrm{E}-\mathrm{BP} 1$ in response to pharmacological treatment $(24,43)$. However, in contrast to these models $(24,43)$, we were unable to observe a differential increase in raptor phosphorylation between trials despite a marked increase in AMPK activity seen in the ER trial.

Two of the best-characterized targets of mTORC1 are S6K1 and 4E-BP1, which, upon phosphorylation by this complex, stimulate translation initiation through distinct mechanisms (36). In the present study, phosphorylation of S6K1 increased immediately after cycling as well as after resistance exercise in both trials despite cycling-induced elevations in AMPK activity in the ER trial. However, the increase in $\mathrm{Thr}^{389}$ phosphorylation, which is specific for mTORC1 $(10,40)$, was not reflected by increased kinase activity until 90 and 180 min into recovery. This suggests that there may be a threshold at which the degree of S6K1 phosphorylation translates into detectable elevations in S6K1 activity. In contrast to S6K1, high-intensity cycling resulted in decreased 4E-BP1 phosphorylation. However, phosphorylation of 4E-BP1 was also repressed after single-mode resistance exercise, and to the same extent as in the ER trial, without a simultaneous increase in AMPK activity. The reason for the divergence between S6K1 and 4E-BP1 is unclear but suggests that these targets are differently regulated $(13,47)$. Nevertheless, the return of 4E-BP1 to basal values and the increase in S6K1 activity, as well as activation of eEF2 during recovery, strongly suggest that mTORC1 activity and protein synthesis was stimulated in both trials, despite prior activation of AMPK by high-intensity interval cycling. Collectively, our data do not support an AMPKmediated inhibition of mTORC1 signaling during recovery in response to concurrent exercise in human muscle.

On the basis of the stimulatory effect on the protein synthetic machinery exerted by both exercise protocols, we expected an increase in the rate of protein synthesis as assessed by the stable-isotope technique. While both modes of exercise induced numeric increases in FSR, they did not reach statistical significance. These results were unexpected, as it is generally accepted that resistance exercise elevates muscle protein syn- 
thesis (4). The reason for this is not readily apparent but may be related to the training status of our subjects and/or the fasted state under which measurements were made. Previous studies have in fact shown a diminished response in resistance-trained subjects $(31,41,42,46)$, and some reports have been unable to detect increases in mixed $(21,31,41)$ as well as myofibrillar $(26,49)$ FSR under both fasted $(26,31)$ and fed $(21,26,41)$ conditions. Our results may be explained, at least in part, by contraction-induced blunting of the synthetic response during exercise $(19,44)$, which may have persisted during early recovery. Consequently, the duration of the FSR measurements may have been too short to detect a significant increase in synthetic rate under the present conditions, i.e., following an overnight fast and $10 \mathrm{~h}$ of infusion under fasting conditions. In light of our results, it must be noted that of the two previous studies that have measured protein synthesis in response to concurrent exercise, neither found a divergent effect compared with single-mode resistance exercise in untrained young (11) and middle-aged (18) subjects.

In addition to a potential inhibition of the protein synthetic response, stimulation of proteolytic pathways involved in protein breakdown could also be responsible for the proposed interference effect. In this context, the ubiquitin-proteasome system (UPS) is believed to be the principal regulator of protein breakdown (37), largely through the muscle-specific E3 ligases MuRF1 and MAFbx (also known as atrogin-1) $(6,22)$. Several studies have reported exercise-induced changes in these genes, thus implicating them as potential mediators of training adaptations (37).

We found that single-mode resistance exercise did not affect mRNA or protein expression of MuRF1 but did decrease both mRNA and protein levels of MAFbx. In contrast, concurrent exercise induced a robust increase in MuRF1 mRNA expression during recovery, which also translated into increased protein expression, a novel finding in human skeletal muscle. The divergent response between the two modes of exercise may be related to the cycling-induced increase in AMPK activity. In support of this notion, pharmacological activation of AMPK has been shown to induce mRNA and protein expression of MuRF1 and MAFbx in rodent cell culture (32, 38,48 ) and in vivo models (32). However, it must be noted that, even though acute AMPK-induced expression of MuRF1 and MAFbx is accompanied by myofibrillar degradation (38), exercise-induced upregulation of these genes may not necessarily result in diminished hypertrophy but may instead be related to myofibrillar remodeling (17). It should also be acknowledged that it is unclear whether the divergent response seen here is due to different contraction modes per se or due to the larger amount of work performed in the ER trial. Nevertheless, our results suggest that concurrent exercise, in contrast to resistance exercise, stimulates the proteolytic machinery, which may have implications for long-term training adaptations.

In summary, high-intensity interval cycling stimulates AMPK activity but does not inhibit subsequent resistance exercise-induced mTORC1 signaling during recovery in human skeletal muscle. This conclusion is supported by similar elevations in S6K1 kinase activity and reductions in eEF2 phosphorylation after both concurrent and single-mode resistance exercise. Moreover, TSC complex assembly was unaltered, and phosphorylation of TSC2 as well as raptor increased similarly after resistance exercise in both conditions, which provides further support for the lack of AMPK-mediated inhibition on mTORC1. Resistance and concurrent exercise induced divergent changes in mRNA and protein expressions of the ubiquitin ligases MuRF1 and MAFbx. Concurrent exercise induced a significant increase in gene and protein expression of MuRF1 as well as a trend for an increase in MAFbx, which was not observed following resistance exercise alone. Collectively, our data suggest that, rather than inhibiting mTORC1 signaling, concurrent exercise may instead interfere with the hypertrophic response by increasing expression of key components involved in muscle breakdown. However, further studies are required to determine whether acute changes in MuRF1 and MAFbx expression result in increased protein breakdown in human skeletal muscle.

\section{ACKNOWLEDGMENTS}

We thank the subjects for their efforts during this study.

\section{GRANTS}

This study was supported by funding from the Swedish National Centre for Research in Sports (CIF P2012-0114) and the Karolinska Institutet (2011 FoBi0780).

\section{DISCLOSURES}

No conflicts of interest, financial or otherwise, are declared by the author(s).

\section{AUTHOR CONTRIBUTIONS}

Author contributions: W.A., M.M., B.E., G.v.H., H.-C.H., and E.B. conception and design of research; W.A., M.M., D.L.H., B.E., G.v.H., and E.B. performed experiments; W.A., M.M., D.L.H., and G.v.H. analyzed data; W.A., M.M., D.L.H., B.E., G.v.H., H.-C.H., and E.B. interpreted results of experiments; W.A. prepared figures; W.A. drafted manuscript; W.A., M.M., D.L.H., B.E., G.v.H., H.-C.H., and E.B. edited and revised manuscript; W.A., M.M., D.L.H., B.E., G.v.H., H.-C.H., and E.B. approved final version of manuscript.

\section{REFERENCES}

1. Antharavally BS, Carter B, Bell PA, Krishna Mallia A. A high-affinity reversible protein stain for Western blots. Anal Biochem 329: 276-280, 2004.

2. Apro W, Wang L, Ponten M, Blomstrand E, Sahlin K. Resistance exercise-induced mTORC1 signaling is not impaired by subsequent endurance exercise in human skeletal muscle. Am J Physiol Endocrinol Metab 305: E22-E32, 2013.

2a.Åstrand PO, Rodahl K. Textbook of Work Physiology. New York: McGraw Hill, 1986.

3. Atherton PJ, Babraj J, Smith K, Singh J, Rennie MJ, Wackerhage H. Selective activation of AMPK-PGC-1alpha or PKB-TSC2-mTOR signaling can explain specific adaptive responses to endurance or resistance training-like electrical muscle stimulation. FASEB $J$ 19: 786-788, 2005.

4. Atherton PJ, Smith K. Muscle protein synthesis in response to nutrition and exercise. J Physiol 590: 1049-1057, 2012.

5. Bergmeyer HU. Methods of Enzymatic Analysis. New York: Academic, 1974.

6. Bodine SC, Latres E, Baumhueter S, Lai VK, Nunez L, Clarke BA, Poueymirou WT, Panaro FJ, Na E, Dharmarajan K, Pan ZQ, Valenzuela DM, DeChiara TM, Stitt TN, Yancopoulos GD, Glass DJ. Identification of ubiquitin ligases required for skeletal muscle atrophy. Science 294: 1704-1708, 2001.

7. Bodine SC, Stitt TN, Gonzalez M, Kline WO, Stover GL, Bauerlein R, Zlotchenko E, Scrimgeour A, Lawrence JC, Glass DJ, Yancopoulos GD. $\mathrm{Akt} / \mathrm{mTOR}$ pathway is a crucial regulator of skeletal muscle hypertrophy and can prevent muscle atrophy in vivo. Nat Cell Biol 3: 1014-1019, 2001.

8. Bolster DR, Crozier SJ, Kimball SR, Jefferson LS. AMP-activated protein kinase suppresses protein synthesis in rat skeletal muscle through down-regulated mammalian target of rapamycin (mTOR) signaling. J Biol Chem 277: 23977-23980, 2002.

9. Borgenvik M, Apro W, Blomstrand E. Intake of branched-chain amino acids influences the levels of MAFbx mRNA and MuRF-1 total protein in 
resting and exercising human muscle. Am J Physiol Endocrinol Metab 302: E510-E521, 2012.

10. Burnett PE, Barrow RK, Cohen NA, Snyder SH, Sabatini DM. RAFT1 phosphorylation of the translational regulators p70 S6 kinase and 4E-BP1. Proc Natl Acad Sci USA 95: 1432-1437, 1998.

11. Carrithers JA, Carroll CC, Coker RH, Sullivan DH, Trappe TA. Concurrent exercise and muscle protein synthesis: implications for exercise countermeasures in space. Aviat Space Environ Med 78: 457-462, 2007.

12. Chevenne D, Trivin F, Porquet $\mathbf{D}$. Insulin assays and reference values. Diabetes Metab 25: 459-476, 1999.

13. Choo AY, Yoon SO, Kim SG, Roux PP, Blenis J. Rapamycin differentially inhibits S6Ks and 4E-BP1 to mediate cell-type-specific repression of mRNA translation. Proc Natl Acad Sci USA 105: 17414-17419, 2008.

14. Coffey VG, Jemiolo B, Edge J, Garnham AP, Trappe SW, Hawley JA. Effect of consecutive repeated sprint and resistance exercise bouts on acute adaptive responses in human skeletal muscle. Am J Physiol Regul Integr Comp Physiol 297: R1441-R1451, 2009.

15. Coffey VG, Pilegaard H, Garnham AP, O'Brien BJ, Hawley JA. Consecutive bouts of diverse contractile activity alter acute responses in human skeletal muscle. J Appl Physiol 106: 1187-1197, 2009.

16. Coffey VG, Zhong Z, Shield A, Canny BJ, Chibalin AV, Zierath JR, Hawley JA. Early signaling responses to divergent exercise stimuli in skeletal muscle from well-trained humans. FASEB J 20: 190-192, 2006.

17. Cunha TF, Moreira JB, Paixao NA, Campos JC, Monteiro AW, Bacurau AV, Bueno CR Jr, Ferreira JC, Brum PC. Aerobic exercise training upregulates skeletal muscle calpain and ubiquitin-proteasome systems in healthy mice. J Appl Physiol (1985) 112: 1839-1846, 2012.

18. Donges CE, Burd NA, Duffield R, Smith GC, West DW, Short MJ, Mackenzie R, Plank LD, Shepherd PR, Phillips SM, Edge JA. Concurrent resistance and aerobic exercise stimulates both myofibrillar and mitochondrial protein synthesis in sedentary middle-aged men. $J$ Appl Physiol 112: 1992-2001, 2012.

19. Dreyer HC, Fujita S, Cadenas JG, Chinkes DL, Volpi E, Rasmussen BB. Resistance exercise increases AMPK activity and reduces 4E-BP1 phosphorylation and protein synthesis in human skeletal muscle. J Physiol 576: 613-624, 2006.

20. Fujii N, Hayashi T, Hirshman MF, Smith JT, Habinowski SA, Kaijser L, Mu J, Ljungqvist O, Birnbaum MJ, Witters LA, Thorell A, Goodyear LJ. Exercise induces isoform-specific increase in 5'AMPactivated protein kinase activity in human skeletal muscle. Biochem Biophys Res Commun 273: 1150-1155, 2000.

21. Gasier HG, Fluckey JD, Previs SF, Wiggs MP, Riechman SE. Acute resistance exercise augments integrative myofibrillar protein synthesis. Metab Clin Exper 61: 153-156, 2011.

22. Gomes MD, Lecker SH, Jagoe RT, Navon A, Goldberg AL. Atrogin-1, a muscle-specific F-box protein highly expressed during muscle atrophy. Proc Natl Acad Sci USA 98: 14440-14445, 2001.

23. Goodman CA, Frey JW, Mabrey DM, Jacobs BL, Lincoln HC, You JS, Hornberger TA. The role of skeletal muscle mTOR in the regulation of mechanical load-induced growth. J Physiol 589: 5485-5501, 2011.

24. Gwinn DM, Shackelford DB, Egan DF, Mihaylova MM, Mery A, Vasquez DS, Turk BE, Shaw RJ. AMPK phosphorylation of raptor mediates a metabolic checkpoint. Mol Cell 30: 214-226, 2008.

25. Hawley JA. Molecular responses to strength and endurance training: are they incompatible? Appl Physiol Nutr Metab 34: 355-361, 2009.

26. Holm L, van Hall G, Rose AJ, Miller BF, Doessing S, Richter EA, Kjaer M. Contraction intensity and feeding affect collagen and myofibrillar protein synthesis rates differently in human skeletal muscle. Am $J$ Physiol Endocrinol Metab 298: E257-E269, 2010.

27. Inoki K, Li Y, Xu T, Guan KL. Rheb GTPase is a direct target of TSC2 GAP activity and regulates mTOR signaling. Genes Dev 17: 1829-1834, 2003.

28. Inoki K, Li Y, Zhu T, Wu J, Guan KL. TSC2 is phosphorylated and inhibited by Akt and suppresses mTOR signaling. Nat Cell Biol 4: 648-657, 2002.

29. Inoki K, Zhu T, Guan KL. TSC2 mediates cellular energy response to control cell growth and survival. Cell 115: 577-590, 2003.

30. Jorgensen SB, Wojtaszewski JF, Viollet B, Andreelli F, Birk JB, Hellsten Y, Schjerling P, Vaulont S, Neufer PD, Richter EA, Pilegaard H. Effects of alpha-AMPK knockout on exercise-induced gene activation in mouse skeletal muscle. FASEB J 19: 1146-1148, 2005.

31. Kim PL, Staron RS, Phillips SM. Fasted-state skeletal muscle protein synthesis after resistance exercise is altered with training. J Physiol 568: 283-290, 2005.
32. Krawiec BJ, Nystrom GJ, Frost RA, Jefferson LS, Lang CH. AMPactivated protein kinase agonists increase mRNA content of the musclespecific ubiquitin ligases MAFbx and MuRF1 in $\mathrm{C}_{2} \mathrm{C}_{12}$ cells. Am J Physiol Endocrinol Metab 292: E1555-E1567, 2007.

33. Leighton B, Blomstrand E, Challiss RA, Lozeman FJ, Parry-Billings M, Dimitriadis GD, Newsholme EA. Acute and chronic effects of strenuous exercise on glucose metabolism in isolated, incubated soleus muscle of exercise-trained rats. Acta Physiol Scand 136: 177-184, 1989.

34. Lundberg TR, Fernandez-Gonzalo R, Gustafsson T, Tesch PA. Aerobic exercise alters skeletal muscle molecular responses to resistance exercise. Med Sci Sports Exerc 44: 1680-1688, 2012.

35. Lundberg TR, Fernandez-Gonzalo R, Tesch PA. Exercise-induced AMPK activation does not interfere with muscle hypertrophy in response to resistance training in men. J Appl Physiol (1985) 116: 611-620, 2014.

36. Ma XM, Blenis J. Molecular mechanisms of mTOR-mediated translational control. Nat Rev 10: 307-318, 2009.

37. Murton AJ, Constantin D, Greenhaff PL. The involvement of the ubiquitin proteasome system in human skeletal muscle remodelling and atrophy. Biochim Biophys Acta 1782: 730-743, 2008.

38. Nakashima K, Yakabe Y. AMPK activation stimulates myofibrillar protein degradation and expression of atrophy-related ubiquitin ligases by increasing FOXO transcription factors in $\mathrm{C} 2 \mathrm{C} 12$ myotubes. Biosci Biotechnol Biochem 71: 1650-1656, 2007.

39. Olesen J, Kiilerich K, Pilegaard H. PGC-1alpha-mediated adaptations in skeletal muscle. Pflügers Arch 460: 153-162, 2010.

40. Pearson RB, Dennis PB, Han JW, Williamson NA, Kozma SC, Wettenhall RE, Thomas G. The principal target of rapamycin-induced p70s6k inactivation is a novel phosphorylation site within a conserved hydrophobic domain. EMBO J 14: 5279-5287, 1995.

41. Phillips SM, Parise G, Roy BD, Tipton KD, Wolfe RR, Tamopolsky MA. Resistance-training-induced adaptations in skeletal muscle protein turnover in the fed state. Can J Physiol Pharmacol 80: 1045-1053, 2002.

42. Phillips SM, Tipton KD, Ferrando AA, Wolfe RR. Resistance training reduces the acute exercise-induced increase in muscle protein turnover. Am J Physiol Endocrinol Metab 276: E118-E124, 1999.

43. Pruznak AM, Kazi AA, Frost RA, Vary TC, Lang CH. Activation of AMP-activated protein kinase by 5-aminoimidazole-4-carboxamide-1-beta-D-ribonucleoside prevents leucine-stimulated protein synthesis in rat skeletal muscle. J Nutr 138: 1887-1894, 2008.

44. Rose AJ, Alsted TJ, Jensen TE, Kobbero JB, Maarbjerg SJ, Jensen J, Richter EA. A $\mathrm{Ca}(2+)$-calmodulin-eEF2K-eEF2 signaling cascade, but not AMPK, contributes to the suppression of skeletal muscle protein synthesis during contractions. J Physiol 587: 1547-1563, 2009.

45. Sancak Y, Thoreen CC, Peterson TR, Lindquist RA, Kang SA, Spooner E, Carr SA, Sabatini DM. PRAS40 is an insulin-regulated inhibitor of the mTORC1 protein kinase. Mol Cell 25: 903-915, 2007.

46. Tang JE, Perco JG, Moore DR, Wilkinson SB, Phillips SM. Resistance training alters the response of fed state mixed muscle protein synthesis in young men. Am J Physiol Regul Integr Comp Physiol 294: R172-R178, 2008.

47. Thoreen CC, Kang SA, Chang JW, Liu Q, Zhang J, Gao Y, Reichling LJ, Sim T, Sabatini DM, Gray NS. An ATP-competitive mammalian target of rapamycin inhibitor reveals rapamycin-resistant functions of mTORC1. J Biol Chem 284: 8023-8032, 2009.

48. Tong JF, Yan X, Zhu MJ, Du M. AMP-activated protein kinase enhances the expression of muscle-specific ubiquitin ligases despite its activation of IGF-1/Akt signaling in $\mathrm{C} 2 \mathrm{C} 12$ myotubes. J Cell Biochem 108: 458-468, 2009.

49. West DW, Burd NA, Coffey VG, Baker SK, Burke LM, Hawley JA, Moore DR, Stellingwerff T, Phillips SM. Rapid aminoacidemia enhances myofibrillar protein synthesis and anabolic intramuscular signaling responses after resistance exercise. Am J Clin Nutr 94: 795-803, 2011.

50. Williamson DL, Bolster DR, Kimball SR, Jefferson LS. Time course changes in signaling pathways and protein synthesis in $\mathrm{C}_{2} \mathrm{C}_{12}$ myotubes following AMPK activation by AICAR. Am J Physiol Endocrinol Metab 291: E80-E89, 2006.

51. Williamson DL, Kubica N, Kimball SR, Jefferson LS. Exercise-induced alterations in extracellular signal-regulated kinase $1 / 2$ and mammalian target of rapamycin (mTOR) signaling to regulatory mechanisms of mRNA translation in mouse muscle. J Physiol 573: 497-510, 2006.

52. Wojtaszewski JF, Nielsen P, Hansen BF, Richter EA, Kiens B. Isoform-specific and exercise intensity-dependent activation of $5^{\prime}$-AMPactivated protein kinase in human skeletal muscle. J Physiol 528: 221226,2000 